Journal of Systems Science and Information

Dec., 2021, Vol. 9, No. 6, pp. 627-659

DOI: $10.21078 /$ JSSI-2021-627-33

\title{
Productivity Analysis for Banks' Merger and Acquisition Using Two-Stage DEA: Evidence from China
}

\author{
Jia LI \\ School of Business, Central South University, Changsha 410083, China \\ E-mail: 191611092@csu.edu.cn \\ Ping WANG \\ School of Business, Central South University, Changsha 410083, China \\ E-mail: pwzdz1207@csu.edu.cn \\ Xiangyang TAO* \\ School of Business, Central South University, Changsha 410083, China \\ E-mail: xiangyangtaoincsu@163.com \\ Yao WEN \\ EMLYON Business School, 23 avenue Guy de Collongue, Ecully Cedex 69134, France \\ E-mail: wenyaophd@163.com
}

\begin{abstract}
Mergers and acquisitions (M\&A) are important parts of banking reform, which can increase the synergies and reduce the costs of the banks. To analyze the effect and importance of the M\&A in the reform period, we measure the productivity change of China's banks who completed M\&A during 20042018, by using a two-stage data envelopment analysis (DEA) method. First, we incorporate the process of deposits producing and the process of profit earning as a two-stage structure of bank's system. Then, we construct a slacks-based measure (SBM) model considering the weak disposability of undesirable outputs to measure the productivity of $14 \mathrm{M} \& \mathrm{~A}$ banks in China. Particularly, we adopt the global Malmquist index (GMI) to evaluate the productivity change of the banks, and analyze the efficiency change (EC) and technical change (TC) for the whole system and individual stages. Additionally, to facilitate making M\&A plans, we classify the M\&A banks to obtain the process they need to improve and the trend they could adopted: (i) We classify them into four categories by the productivity of two individual stages; (ii) We also classify them into four categories by EC and TC. Finally, the policy recommendations for $\mathrm{M} \& \mathrm{~A}$ banks are given.
\end{abstract}

Keywords data envelopment analysis; merger and acquisition; slack-based measure; undesirable outputs; China's banking

\section{Introduction}

As a vital industry in a country's economy, the banking industry plays an important role in the process of financial development. In China, banks are divided into five categories according

Received June 27, 2021, accepted October 19, 2021

Supported by National Natural Science Foundation of China (71871223, 72171238, 71991465), Natural Science Foundation of Hunan Province (2021JJ20072)

*Corresponding author 
to China Banking and Insurance Regulatory Commission (CBIRC): Large commercial banks (six state-owned banks), joint-stock commercial banks, city commercial banks, rural financial institutions and other types of financial institutions. The China's banking sector undergoes noteworthy financial reform, which significantly metamorphoses the banking system ${ }^{[1]}$. The reform had experienced two stages before $2003^{[2]}$. China's specialized banking system established from the first stage during 1978-1992. Specifically, four wholly state-owned specialized banks, commonly called the 'Big Four' were established or operated independently. But they were not fully profit-oriented banks and still carried political obligations. During 1993-2002, the second round of banking reform was announced by the State Council. Policy banks took over policy-related business from Big Four banks. Thus, the four state-owned banks were transformed into fully commercial banks. From 2003, a new round of banking reform launched as large state-owned commercial banks transform to share holds. Banks in China began to list. The banking reform never stopped, for instance, supply-side structural reform, fiscal and tax system reform, and so on. Up to now, the reform of China's banking has verified to improve the efficiency and optimize the business environment. To late 2020, China's banking sector has had the largest scale of assets among the global banking sectors, with total assets of 312 trillion yuan according to the official report by CBIRC.

In the process of banking reform, some banks unite several individual banks or capture other banks to become a new bank ${ }^{[3]}$, and these transactions are called Mergers and acquisitions $(M \& A) . M \& A$ is an effective way to ascend value and synergies of banks ${ }^{[4,5]}$, strengthen advantages $^{[6]}$, and additionally achieve fintech-driven technological progress ${ }^{[7]}$. Therefore, banks seek M\&A as one of the first strategies for promoting performance in the banking industry ${ }^{[8-10]}$. Current literatures have discussed the effect of M\&A on banks performance. The M\&A of the largest bank between 1985 and 1996 resulted in the increase of operating performance ${ }^{[11]}$. Zarei, et al. ${ }^{[9]}$ agreed that M\&A enhanced the performance of banks in Iranian through promoting entrepreneurial orientation. Sathishkumar and Tamby ${ }^{[3]}$ examined the relationship between Lebanese banks' M\&A and their financial performance, and showed mixed impacts on different profitability indicators. Rezitis ${ }^{[12]}$ indicated negative influence of M\&A on technical efficiency and productivity growth. Although the results are mixed, M\&A implement is still one of the banking necessities to improve their performance. Analyzing the effect of M\&A on bank performance is necessary and helpful for the further M\&A implementation, and is also our focus in this study.

A prevalent methodology to measure bank performance is data envelopment analysis (DEA) in previous literature ${ }^{[13]}$. DEA is a non-parametric approach to address the problem of evaluating the relative efficiency of decision making units (DMUs) with multiple inputs and outputs ${ }^{[14-18]}$. It was first proposed by Charnes, et al. ${ }^{[19]}$ as a linear programming model, and many scholars proposed various DEA models in succession. Such as Banker, et al. ${ }^{[20]}$ proposed BCC model to measure DMUs under variable returns to scale (VRS) and Tone ${ }^{[21]}$ proposed slacks-based measure (SBM) model to directly measure the slacks of inputs and outputs of DMUs. By using DEA, several previous studies explore the merger effects on banks performance. For example, Avkiran ${ }^{[2]}$ measured the relative efficiencies of Australian trading banks from 1986 to 1995 and indicate a gradual rise in efficiencies after the merger. Sufian ${ }^{[23]}$ suggested that the M\&A has 
resulted in a higher mean technical efficiency of the Malaysian banking sector post-merger. In emerging countries, M\&A leads to efficiency improvements for the combined entity, and China is the only exception which experienced uninterrupted improvement throughout the period of 2002-2009 ${ }^{[8]}$. Furthermore, variable returns to scale (VRS) is assumed accounting for the situation in banking, where increase by a proportion in inputs produce not the same proportionate increase in outputs.

Ignoring the internal processes (i.e., stages) may provide inaccurate efficiency scores for evaluated DMUs, e.g., a DMU is efficient even though some of its individual stages are not ${ }^{[24]}$. Moreover, it is not able to identify the cause for the inefficiency of the whole DMU when we look it as a black box ${ }^{[25,26]}$. Thus, some scholars open the black box of bank production system and propose network DEA. Based on the two-stage DEA approach, which is one kind of the network DEA, many studies concentrate on the measurement and analysis of the potential gains of M\&A in bank industry. For example, Xie, et al. ${ }^{[27]}$ decomposed the potential efficiency gains in M\&A by looking commercial banks in China as two-stage production systems, Wanke, et al. ${ }^{[17]}$ applied two-stage DEA to measure the bank efficiency and support that acquiring banks are more efficient than the target banks from the evidence of four merger cases. These studies give no analysis on the relationship between M\&A and bank performance, such as the difference between individual stages. In addition, few of them discuss the effect of M\&A on performance of the banks in China.

To alleviate above deficiencies existing in current literatures, we focus on analyzing the productivity change of China's banks who have completed M\&A during 2004-2018. First, we identify a two-stage structure of bank's system, incorporating the process of deposits producing and the process of profit earning. Then, in order to describe the Null-Joint relationship between outputs of banks, we establish a network DEA model considering the weak disposability assumptions of undesirable outputs and apply it in China's banking based on practical data of M\&A banks during M\&A period. To analyze the performance changes of these banks during M\&A period, we frame a dynamic investigation and calculate two internal stages' productivities and productivity changes. Thus, we leverage the decomposition of SBM and global Malmquist index (GMI), to obtain the process they need to improve and the trend they could take advantage. Based on above analysis, we provide policy recommendations for M\&A banks in China. By doing these, compared with current studies, our study can provide a more nuanced view of M\&A influence on performance of China's banking industry.

This paper is organized as follows. Section 2 introduces the preliminary methodology and Section 3 introduces our proposed model under the weak disposability assumption of undesirable outputs. Section 4 presents the application on M\&A banks in China during 2004 to 2019. Section 5 gives detailed discussions about the application. Section 6 concludes our study.

\section{Preliminaries}

\subsection{Efficiency Measurement Models}

In order to introduce a two-stage DEA model with undesirable outputs, we first assume strong disposability on undesirable outputs. For each $\mathrm{DMU}_{0}$ evaluated, stage 1 uses $m$ inputs $\boldsymbol{x}_{0}=\left(x_{01}, x_{02}, \cdots, x_{0 m}\right)$ to produce $h$ outputs $\boldsymbol{z}_{0}=\left(z_{01}, z_{02}, \cdots, z_{0 h}\right)$; stage 2 uses the 
outputs from stage 1 to produce $s$ desirable outputs $\boldsymbol{y}_{\mathbf{0}}=\left(y_{01}, y_{02}, \cdots, y_{0 s}\right)$ and $f$ undesirable outputs $\boldsymbol{u}_{\mathbf{0}}=\left(u_{01}, u_{02}, \cdots, u_{0 f}\right)$. Like the model proposed by An, et al. ${ }^{[28]}$, we denote $s_{i}^{-}$, $s_{r}^{+}$and $s_{d}^{\prime-}$ as slacks of the $i$ th input, the $r$ th desirable output and the $d$ th undesirable output of the system, respectively. The two-stage SBM model with undesirable outputs is given as follows:

$$
\begin{array}{ll}
\min & \rho=\frac{1-\frac{1}{m} \sum_{i=1}^{m} \frac{s_{i}^{-}}{x_{0 i}}}{1+\frac{1}{s+f}\left(\sum_{r=1}^{s} \frac{s_{r}^{+}}{y_{0 r}}+\sum_{d=1}^{f} \frac{s_{d}^{\prime}}{u_{0 d}}\right)} \\
\text { s.t. } & \sum_{j=1}^{n} \lambda_{j}^{1} x_{j i}+s_{i}^{-}=x_{0 i}, i=1,2, \cdots, m, \\
& \sum_{j=1}^{n} \lambda_{j}^{2} y_{j r}-s_{r}^{+}=y_{0 r}, r=1,2, \cdots, s, \\
& \sum_{j=1}^{n} \lambda_{j}^{2} u_{j d}+s_{d}^{\prime-}=u_{0 d}, d=1,2, \cdots, f, \\
& \sum_{j=1}^{n} \lambda_{j}^{1} z_{j p} \geq z_{0 p}, p=1,2, \cdots, h, \\
& \sum_{j=1}^{n} \lambda_{j}^{2} z_{j p} \leq z_{0 p}, p=1,2, \cdots, h, \\
& \sum_{j=1}^{n} \lambda_{j}^{1}=1, \\
& \sum_{j=1}^{n} \lambda_{j}^{1}=1, \\
& \lambda_{j}^{1}, \lambda_{j}^{2}, s_{i}^{-}, s_{r}^{+}, s_{d}^{\prime-} \geq 0, j=1,2, \cdots, n, i=1,2, \cdots, m, r=1,2, \cdots, s,
\end{array}
$$

where $\rho$ represents the efficiency of $\mathrm{DMU}_{0}$, and $\lambda_{j}^{1}$ and $\lambda_{j}^{2}$ are intensity multiplier of stage 1 and stage 2. Denote $\left(\lambda_{j}^{1 *}, \lambda_{j}^{2 *}, s_{i}^{-*}, s_{r}^{+*}, s_{d}^{\prime-*}\right)$ as the optimal solution of model (1). As An, et al. ${ }^{[28]}$ noted, the gap between the two optimized intermediate variables (outputs of the stage 1 and inputs of the stage 2) needs to be reduced. According to the optimal solution above, the intermediate measures slacks can be obtained by the following integrated model.

$$
\max \sum_{p=1}^{h} \frac{s_{p}^{1+}}{z_{0 p}}+\sum_{p=1}^{h} \frac{s_{p}^{2-}}{z_{0 p}}
$$

s.t. (stage 1 constraints)

$$
\begin{aligned}
& \sum_{j=1}^{n} \lambda_{j}^{1} x_{j i}+s_{i}^{-*}=x_{0 i}, i=1,2, \cdots, m, \\
& \sum_{j=1}^{n} \lambda_{j}^{1} z_{j p}-s_{p}^{1+}=z_{0 p}, p=1,2, \cdots, h \\
& \sum_{j=1}^{n} \lambda_{j}^{1}=1
\end{aligned}
$$




$$
\begin{aligned}
& \lambda_{j}^{1} \geq 0, j=1,2, \cdots, n, \\
& \text { (stage } 2 \text { constraints) } \\
& \sum_{j=1}^{n} \lambda_{j}^{2} z_{j p}+s_{p}^{2-}=z_{0 p}, p=1,2, \cdots, h, \\
& \sum_{j=1}^{n} \lambda_{j}^{2} y_{j r}-s_{r}^{+*}=y_{0 r}, r=1,2, \cdots, s, \\
& \sum_{j=1}^{n} \lambda_{j}^{2} u_{j d}+s_{d}^{-*}=u_{0 d}, d=1,2, \cdots, f, \\
& \sum_{j=1}^{n} \lambda_{j}^{2} u_{j d}+s_{d}^{-*}=u_{0 d}, d=1,2, \cdots, f, \\
& \sum_{j=1}^{n} \lambda_{j}^{1}=1, \\
& \lambda_{j}^{2} \geq 0, j=1,2, \cdots, n,
\end{aligned}
$$

$s_{p}^{1+*}$ and $s_{p}^{2-*}$ are the slacks of intermediate variables in stage 1 and stage 2 , respectively. Based on the optimal values above, the slacks-based efficiency values of whole system, stage 1 and stage 2 are defined as follows:

$$
\begin{aligned}
\rho^{*} & =\frac{1-\frac{1}{m} \sum_{i=1}^{m} \frac{s_{i}^{-*}}{x_{0 i}}}{1+\frac{1}{s+f}\left(\sum_{r=1}^{s} \frac{s_{r}^{+*}}{y_{0 r}}+\sum_{d=1}^{f} \frac{s_{d}^{\prime-*}}{u_{0 d}}\right)}, \\
\rho_{1}^{*} & =\frac{1-\frac{1}{m} \sum_{i=1}^{m} \frac{s_{i}^{-*}}{x_{0 i}}}{1+\frac{1}{h} \sum_{p=1}^{h} \frac{s_{p}^{1+*}}{z_{0 p}}}, \\
\rho_{2}^{*} & =\frac{1-\frac{1}{h} \sum_{p=1}^{h} \frac{s_{p}^{2-*}}{z_{k p}}}{1+\frac{1}{s+f}\left(\sum_{r=1}^{s} \frac{s_{r}+*}{y_{0 r}}+\sum_{d=1}^{f} \frac{s_{d}^{\prime-*}}{u_{0 d}}\right)} .
\end{aligned}
$$

Models (1) and (2) are constructed based on the strong disposability of undesirable outputs. They allow the case in which descend (ascend) undesirable outputs but ascend (descend) desirable outputs, and treat undesirable outputs as the inputs of the whole system but the inputs of the second stage in model (2). However, outputs usually ascend or descend simultaneously and the undesirable outputs are actually produced after the second stage. Therefore, we select the assumption of weak disposability. There is a Null-Joint relationship under the weak disposability, which means when undesirable outputs are eliminated, the inputs are null ${ }^{[29]}$. In detail, only if eliminate inputs, can undesirable outputs be cleared, and desirable outputs are not produced. In terms of Shephard ${ }^{[30]}$, when the production technology is presented by $P(\boldsymbol{x})=\left\{(\boldsymbol{y}, \boldsymbol{u}) \mid \boldsymbol{x}\right.$ can produce $\left.(\boldsymbol{y}, \boldsymbol{u}), \boldsymbol{x} \in R_{+}^{m}\right\}$, the definition of weak disposability is as follows.

Definition 1 Undesirable outputs are weakly disposable if $(\boldsymbol{y}, \boldsymbol{u}) \in P(\boldsymbol{x})$ and $0 \leq \theta \leq 1$ imply $(\theta \boldsymbol{y}, \theta \boldsymbol{u}) \in P(\boldsymbol{x})$.

On the basis of Definition 1, undesirable outputs could be reduced by $\theta$ through scaling down 
of the activity level, which can be simply expressed in SBM approach ${ }^{[31]}$. Then, we use the model as follows to measure the efficiency of $\mathrm{DMU}_{0}$ by the abatement potential in undesirable outputs under VRS.

$$
\begin{array}{ll}
\min & \varphi \\
\text { s.t. } & \sum_{j=1}^{n} \theta_{j} \lambda_{j} y_{j r} \geq y_{r 0}, r=1,2, \cdots, s, \\
& \sum_{j=1}^{n} \theta_{j} \lambda_{j} u_{j d}=\varphi u_{0 d}, d=1,2, \cdots, f, \\
& \sum_{j=1}^{n} \lambda_{j} x_{j i} \leq x_{0 i}, \quad i=1,2, \cdots, m, \\
& \sum_{j=1}^{n} \lambda_{j}=1, \\
& \lambda_{j} \geq 0, j=1,2, \cdots, n, \\
& 0 \leq \theta_{j} \leq 1, j=1,2, \cdots, n .
\end{array}
$$

The scalar factor $\varphi$ in constraint (6.b) is maximum radial reduction of undesirable output. It indicates the potential capacity to descent undesirable output for $\mathrm{DMU}_{0}$. This model is simply measured the radial reduction of undesirable outputs, but the inefficiency of inputs and desirable outputs are not considered.

\subsection{Global Malmquist Index}

The Malmquist productivity index (MI) can be used to measure the changes of performance over two periods ${ }^{[32]}$, and it was applied in many fields, such as, environment ${ }^{[33,34]}$, agriculture $^{[35,36]}$, economy ${ }^{[37]}$, airports ${ }^{[38]}$, technology innovation ${ }^{[39]}$. Pastor and Lovell ${ }^{[40]}$ addressed the no circular problem between periods and proposed GMI measuring DMUs of all periods based on the same production frontier facet. We apply GMI to make dynamic analysis based on our balanced panel dataset. A set of $n$ DMUs that have the same two-stage structure

and cover $q$ periods is considered. A contemporaneous production possible set (PPS) of the $t-t h$ period is defined as $T^{t}=\left\{\left(x^{t}, y^{t}\right) \mid x^{t}\right.$ can produce $\left.y^{t}\right\}, t=1,2, \cdots, q$. The global PPS is defined as $T^{G}=T^{1} \cup \cdots \cup T^{q}$. A GMI is defined on $T^{G}$ as follows:

$$
\operatorname{GMI}\left(x^{t}, y^{t}, x^{t+1}, y^{t+1}\right)=\frac{\rho^{g}\left(x^{t+1}, y^{t+1}\right)}{\rho^{g}\left(x^{t}, y^{t}\right)} .
$$

where $\rho^{g}\left(x^{t}, y^{t}\right)$ is the relative efficiency of the DMU in the $t$ th period based on $T^{G}$. GMI $>1$ represents that a DMU improves productivity between two period. Though the measurement of productivity change refers to the global frontier, the usual efficiency change (EC) (also known as catch-up effect) is measured on the contemporaneous PPS, which is denoted as follows:

$$
\mathrm{EC}\left(x^{t}, y^{t}, x^{t+1}, y^{t+1}\right)=\frac{\rho^{t+1}\left(x^{t+1}, y^{t+1}\right)}{\rho^{t}\left(x^{t}, y^{t}\right)},
$$


where $\rho^{t}\left(x^{t}, y^{t}\right)$ states the contemporaneous efficiency of DMU in the $t$ th period based on $T^{t}$. EC could be decomposed from GMI, together with technical change (TC) as follows:

$$
\begin{aligned}
\operatorname{GMI}\left(x^{t}, y^{t}, x^{t+1}, y^{t+1}\right) & =\frac{\rho^{t+1}\left(x^{t+1}, y^{t+1}\right)}{\rho^{t}\left(x^{t}, y^{t}\right)} \times\left[\frac{\rho^{g}\left(x^{t+1}, y^{t+1}\right)}{\rho^{g}\left(x^{t}, y^{t}\right)} \times \frac{\rho^{t}\left(x^{t}, y^{t}\right)}{\rho^{t+1}\left(x^{t+1}, y^{t+1}\right)}\right] \\
& =\operatorname{EC}\left(x^{t}, y^{t}, x^{t+1}, y^{t+1}\right) \times \frac{\rho^{g}\left(x^{t+1}, y^{t+1}\right) / \rho^{t+1}\left(x^{t+1}, y^{t+1}\right)}{\rho^{g}\left(x^{t}, y^{t}\right) / \rho^{t}\left(x^{t}, y^{t}\right)} \\
& =\mathrm{EC}\left(x^{t}, y^{t}, x^{t+1}, y^{t+1}\right) \times \mathrm{TC}\left(x^{t}, y^{t}, x^{t+1}, y^{t+1}\right),
\end{aligned}
$$

where EC $>1$ implies the efficiency progress and TC $>1$ implies technical progress, vice versa. The $\rho^{g}\left(x^{t}, y^{t}\right) / \rho^{t}\left(x^{t}, y^{t}\right)$ part of TC suggests the best practice gap between the contemporaneous technology frontier and global technology frontier. Moreover, the GMI and its decomposition of stage 1 or stage 2 are given by replacing the $\rho$ in the formulas above by $\rho_{1}$ or $\rho_{2}$.

\section{The Proposed SBM Model with Disposable Undesirable Outputs}

Based on the models and the weak disposability assumption of undesirable final outputs above, the PPS of the two-stage system under VRS can be defined as follows.

$$
\begin{aligned}
\operatorname{PPS}=\{(X, Z, Y, U): & \sum_{j=1}^{n} \lambda_{j}^{1} x_{j i} \geq x_{0 i}, i=1,2, \cdots, m, \\
& \sum_{j=1}^{n} \lambda_{j}^{1} z_{j p}=z_{0 p}, p=1,2, \cdots, h, \\
& \sum_{j=1}^{n} \lambda_{j}^{2} z_{j p}=z_{0 p}, p=1,2, \cdots, h, \\
& \sum_{j=1}^{n} \theta_{j}^{2} \lambda_{j}^{2} y_{j r} \geq y_{0 r}, r=1,2, \cdots, s, \\
& \sum_{j=1}^{n} \theta_{j}^{2} \lambda_{j}^{2} u_{j d}=u_{0 d}, d=1,2, \cdots, f, \\
& \sum_{j=1}^{n} \lambda_{j}^{1}=1, \\
& \sum_{j=1}^{n} \lambda_{j}^{2}=1, \\
& \left.\lambda_{j}^{1}, \lambda_{j}^{2} \geq 0, \theta_{j}^{2} \in[0,1], j=1,2, \cdots, n\right\} .
\end{aligned}
$$

(10a) and (10b) are restrictions for stage 1 and (10c) to (10e) are constraints for stage 2. (10b) and (10c) are fixed links between the two stages ${ }^{[41]}$. Subsequently, we extend the two-stage SBM model with undesirable outputs as follows.

$$
\min \rho=\frac{1-\frac{1}{m} \sum_{i=1}^{m} \frac{s_{i}^{-}}{x_{0 i}}}{1+\frac{f}{s+f}(\varphi-1)+\frac{1}{s+f} \sum_{r=1}^{s} \frac{s_{r}^{+}}{y_{0 r}}}
$$




$$
\begin{array}{ll} 
& \sum_{j=1}^{n} \lambda_{j}^{1} x_{j i}+s_{i}^{-}=x_{0 i}, i=1,2, \cdots, m, \\
& \sum_{j=1}^{n} \theta_{j}^{2} \lambda_{j}^{2} y_{j r}-s_{r}^{+}=y_{0 r}, r=1,2, \cdots, s, \\
& \sum_{j=1}^{n} \theta_{j}^{2} \lambda_{j}^{2} u_{j d}=\varphi u_{0 d}, d=1,2, \cdots, f, \\
& \sum_{j=1}^{n} \lambda_{j}^{1} z_{j p}=z_{0 p}, p=1,2, \cdots, h, \\
& \sum_{j=1}^{n} \lambda_{j}^{2} z_{j p}=z_{0 p}, p=1,2, \cdots, h, \\
& \sum_{j=1}^{n} \lambda_{j}^{1}=1, \\
& \sum_{j=1}^{n} \lambda_{j}^{2}=1, \\
& \varphi, \theta_{j}^{2} \in[0,1], j=1,2, \cdots, n, \\
& \lambda_{j}^{1}, \lambda_{j}^{2}, s_{i}^{-}, s_{r}^{+} \geq 0, j=1,2, \cdots, n, i=1,2, \cdots, m, r=1,2, \cdots, s .
\end{array}
$$

Model (11) is a nonlinear program, and we can transform it into a linear program by setting $\theta^{2} \lambda^{2}=\alpha^{2}$ and $\lambda^{2}=\alpha^{2}+\beta^{2}$ first ${ }^{[42]}$, and $t=\frac{1}{1+\frac{f}{s+f}(\varphi-1)+\frac{1}{s+f} \sum_{r=1}^{s} \frac{s_{r}^{+}}{y_{k r}}},\left(\Lambda^{1}, \Lambda^{2}, \mathcal{M}^{2}, S^{-}, S^{+}, \phi\right)=$ $t *\left(\lambda^{1}, \theta^{2}, \lambda^{2}, \lambda^{2}, s^{-}, s^{+}, \varphi\right)^{[19]}$. By doing these, we obtain following model.

$$
\min \rho=t-\frac{1}{m} \sum_{i=1}^{m} \frac{S_{i}^{-}}{x_{0 i}}
$$

s.t. $\quad t+\frac{f}{s+f}(\phi-t)+\frac{1}{s+f} \sum_{r=1}^{s} \frac{S_{r}^{+}}{y_{0 r}}=1$,

$$
\begin{aligned}
& \sum_{j=1}^{n} \Lambda_{j}^{1} x_{j i}+S_{i}^{-}=t x_{0 i}, i=1,2, \cdots, m, \\
& \sum_{j=1}^{n} \Lambda_{j}^{2} y_{j r}-S_{r}^{+}=t y_{0 r}, r=1,2, \cdots, s, \\
& \sum_{j=1}^{n} \Lambda_{j}^{2} u_{j d}=\phi u_{0 d}, d=1,2, \cdots, f, \\
& \sum_{j=1}^{n} \Lambda_{j}^{1} z_{j p}=t z_{0 p}, p=1,2, \cdots, h, \\
& \sum_{j=1}^{n}\left(\Lambda_{j}^{1}+\mathcal{M}_{j}^{2}\right) z_{j p}=t z_{0 p}, p=1,2, \cdots, h, \\
& \sum_{j=1}^{n} \Lambda_{j}^{1}=t,
\end{aligned}
$$




$$
\begin{aligned}
& \sum_{j=1}^{n}\left(\Lambda_{j}^{2}+\mathcal{M}_{j}^{2}\right)=t, \\
& t, \Lambda_{j}^{1}, \mathcal{M}_{j}^{1}, \Lambda_{j}^{2}, \mathcal{M}_{j}^{2}, S_{i}^{-}, S_{r}^{+}, \phi \geq 0, j=1,2, \cdots, n, i=1,2, \cdots, m, r=1,2, \cdots, s .
\end{aligned}
$$

For which the optimal value $s_{i}^{-}$and $s_{r}^{+}$are slacks of inputs and final desirable outputs, and $\varphi$ is a radial improvement variable of undesirable outputs. $\left(S_{i}^{-*}, \phi^{*}, S_{r}^{+*}, t^{*}\right)$ marks optimal solution by solving them in model (12), and $\left(s_{i}^{-*}, \varphi^{*}, s_{r}^{+*}\right)=t^{*} /\left(S_{i}^{-*}, \phi^{*}, S_{r}^{+*}\right)$. Based on the optimal solution, we define the efficiency value of whole system as follows:

$$
\rho^{*}=\frac{1-\frac{1}{m} \sum_{i=1}^{m} \frac{s_{i}^{-*}}{x_{0 i}}}{1+\frac{f}{s+f}\left(\varphi^{*}-1\right)+\frac{1}{s+f} \sum_{r=1}^{s} \frac{s_{r}^{+*}}{y_{0 r}}} .
$$

Efficient DMU is the well-performed unit, they have the best performance among all evaluated DMUs. Therefore, the definition of the efficient DMU is as follows:

Definition $2 \rho^{*}$ is the overall efficiency of evaluated $\mathrm{DMU}_{0}$. If $\rho^{*}=1$, the $\mathrm{DMU}_{0}$ is efficient in whole system.

The formula for the overall efficiency $\rho^{*}$ can be interpreted as a multiplier form and divided into the efficiencies of two individual stages as follows.

$$
\begin{aligned}
\rho_{1}^{*} & =1-\frac{1}{m} \sum_{i=1}^{m} \frac{s_{i}^{-*}}{x_{0 i}} \\
\rho_{2}^{*} & =\frac{1}{1+\frac{f}{s+f}\left(\varphi^{*}-1\right)+\frac{1}{s+f} \sum_{r=1}^{s} \frac{s_{r}^{+*}}{y_{0 r}}} .
\end{aligned}
$$

In the similar way, the definition of efficient stage is:

Definition $3 \quad \rho_{1}^{*}$ is the efficiency of evaluated $D M U_{0}$ 's stage 1 and $\rho_{2}^{*}$ is the efficiency of evaluated $\mathrm{DMU}_{0}$ 's stage 2. If $\rho_{1}^{*}=1$, the stage 1 of $\mathrm{DMU}_{0}$ is efficient and if $\rho_{2}^{*}=1$, the stage 2 of $\mathrm{DMU}_{0}$ is efficient.

The relationship between $\rho^{*}, \rho_{1}^{*}$ and $\rho_{2}^{*}$ is described in the following.

Definition $4 \mathrm{DMU}_{0}$ is overall efficient if and only if the stage efficiencies of $\mathrm{DMU}_{0}$ are 1 , i.e., $\rho_{1}^{*}=\rho_{2}^{*}=1$.

\section{Application to Banking Industry in China}

As noted by Wanke, et al. ${ }^{[43]}$, banks contain several production processes in many real applications. As Wang, et al. ${ }^{[44]}$ pointed, the operation of bank includes two processes, namely, the capital collection and investment. Based on this, many scholars study the performance of banks, looking them as two-stage organizations. In detail, commercial banks accept deposits from the public and then make loans or investments to gains profits (Zha, et al. ${ }^{[45]}$ ). Similar to previous studies, we divide the production system of China's banks into the accumulation process and earning process, as shown in Figure 1. 


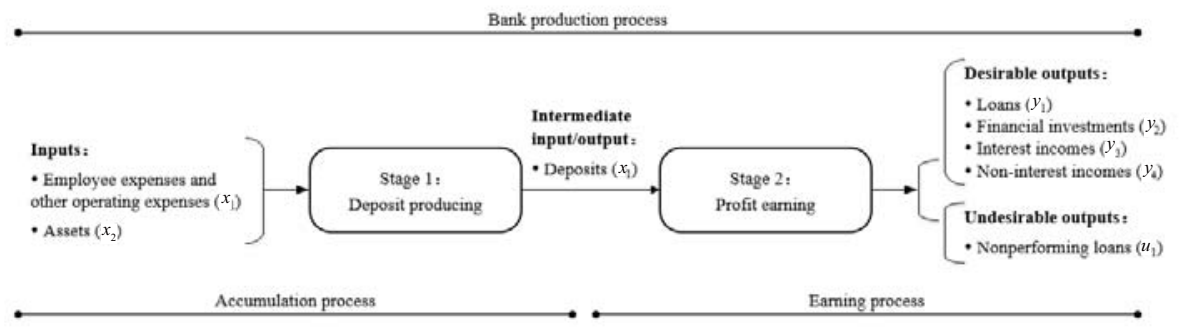

Figure 1 Two-stage production system of bank

The accumulation process describes deposits producing, which accumulates funds for banks. The earning process describes profit earning, which utilizes the deposit to issue loans, make investments and gain incomes. In this section, we introduce the rationale for the variable selection in the first part, then introduce the data and results of measurement in the following parts.

\subsection{Input and Output Selection}

Banking ranked second in the latest application fields by the numbers of DEA-related journal $\operatorname{articles}^{[13]}$. There are three universal approaches to measure the performance of banks. Banks in production approach are regards as service producers, using capital and labor to produce different kinds of products, in particular loans and deposits ${ }^{[46-49]}$. The intermediation approach is used in most DEA studies to concern about the financial intermediary role of banks ${ }^{[50]}$. The inputs and outputs are specified based on the transformation process and preference in terms of the market value of intermediary services ${ }^{[51]}$. The profitability approach is quite similar to the production approach, but the outputs of profitability approach, as suggested, are more profit-oriented, such as interest income and non-interest income ${ }^{[49,52]}$.

To give the theoretical basis of input and output selection, Table 1 summarizes the variable selection of bank system with two-stage structure in previous researches. The variables are classified into inputs, intermediate outputs and final outputs. The inputs in the first stage produce intermediate outputs which are transformed in the second stage of production to final outputs. However, the variable selections of two individual stages are different. With general agreement amongst the previous variable selections of the first stage, they adopted production approach considering banks using capital and labor (inputs) to produce deposit (intermediate output). Considering the deposit as intermediation variable is the solution to deposit dilemma ${ }^{[53]}$. Nevertheless, two main inconsistences are exposed in the second stage. First, some studies measured profitability but others measured marketability of banks. Second, discrepancy presents in whether specifying the investments indicator and non-performing loans (undesirable final output) or not.

The traditional indicator specifications on banks are difficult to clearly fit in China ${ }^{[54]}$. Thus, we select variables and construct a novel bank system with two-stage structure, which are shown in Table 2. The variable selection of the first stage follows with the general agreement, while the variables of the second stage are selected by solving the inconsistences above. First, we pay more attention to the profitability of banks, because the marketability measurement is 
Productivity Analysis for Banks' Merger and Acquisition Using Two-Stage DEA: Evidence from China 637

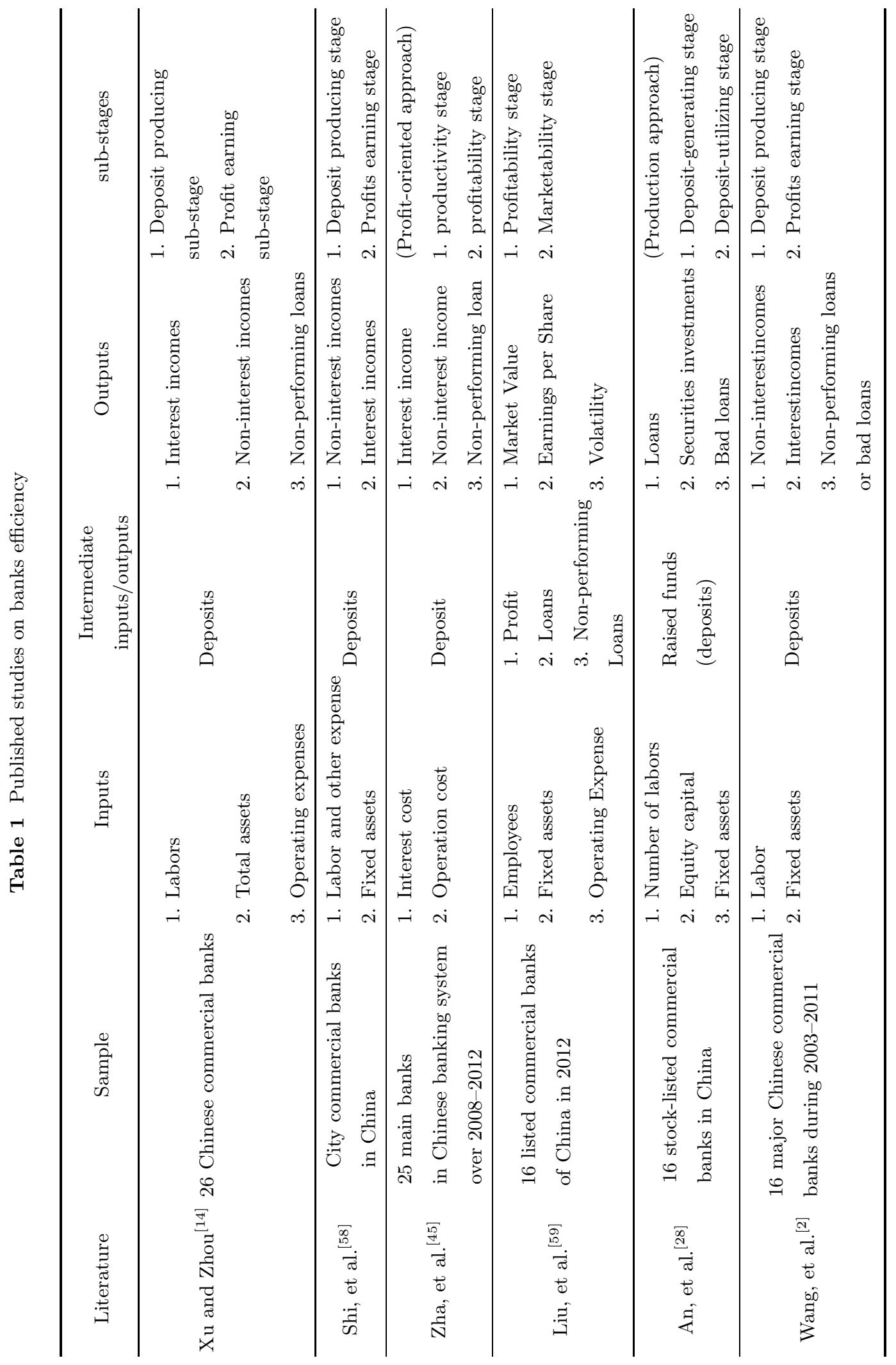




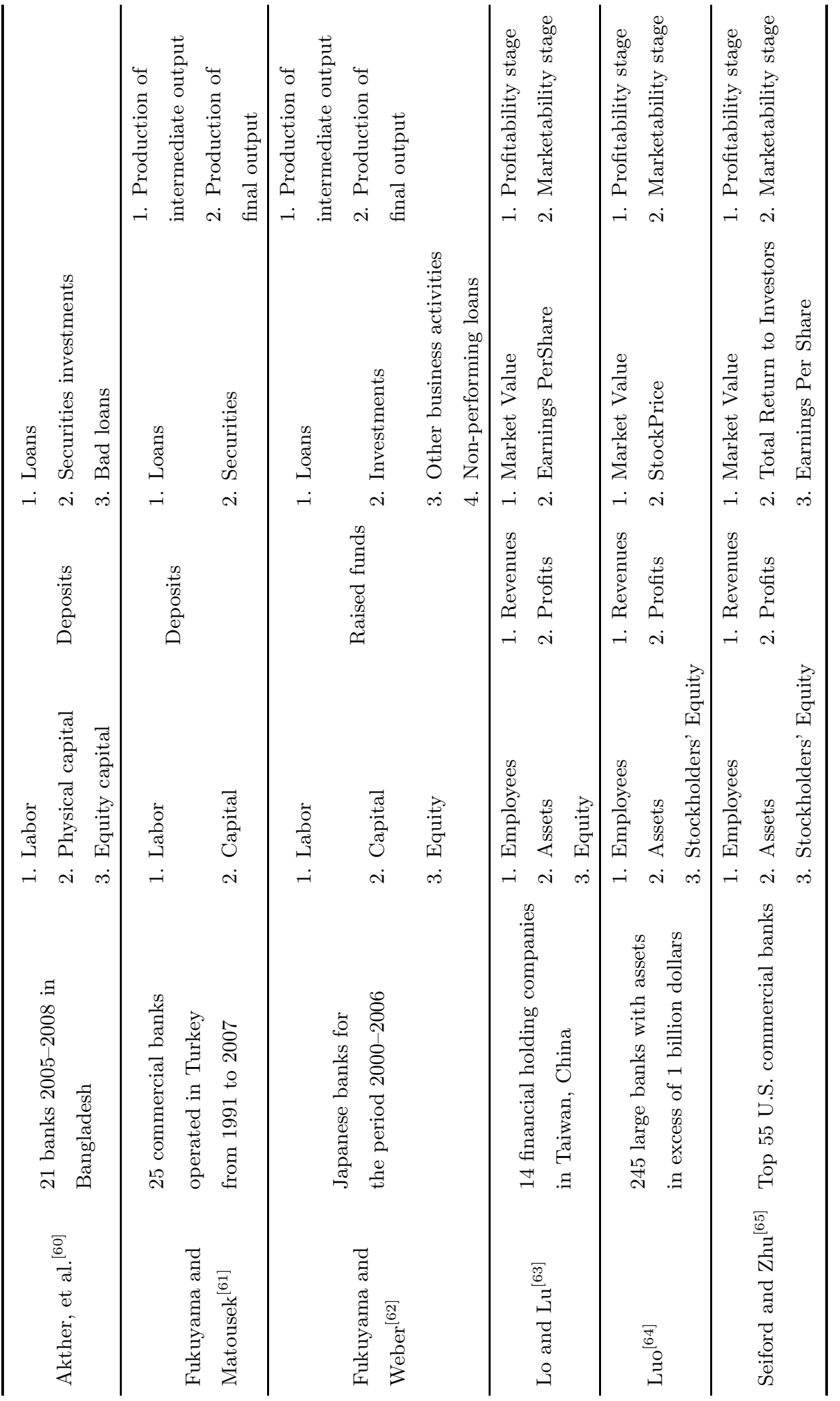


Table 2 Variables of inputs, intermediate input/output, desirable outputs and undesirable outputs

\begin{tabular}{|c|c|c|c|}
\hline Indicators & & Variables & Units \\
\hline \multirow{2}{*}{ Inputs } & $x_{1}$ & Management fees & 10 billion CNY \\
\hline & $x_{2}$ & Total assets & 10 billion CNY \\
\hline intermediate input/output & $z_{1}$ & Deposits & 10 billion CNY \\
\hline \multirow{4}{*}{ desirable outputs } & $y_{1}$ & Interest income & 10 billion CNY \\
\hline & $y_{2}$ & Non-interest income & 10 billion $\mathrm{CNY}$ \\
\hline & $y_{3}$ & Loans & 10 billion $\mathrm{CNY}$ \\
\hline & $y_{4}$ & Financial investment & 10 billion $\mathrm{CNY}$ \\
\hline undesirable outputs & $u_{1}$ & Non-performing loans & 10 billion CNY \\
\hline
\end{tabular}

based on the complicated stock market. When they measured the profitability, scholars tend to allow deposits to produce portfolio of loans and incomes (final outputs) which are the outputs specified in intermediation approach. Second, we select the two indicators, investments and nonperforming loans, from the perspective of banks' operations that help an accurate understanding of bank's profit earning process. Investment is an essential operation as mentioned above, and non-performing loans has been proved significantly negative influence on bank efficiency ${ }^{[55,56]}$. Another reason could be illustrated by classifying operations. According to the composition of balance sheet, the banking operations in China are classified into three types - Asset business, liability business and intermediate business ${ }^{[57]}$. Investments and non-performing loans, together with loans, characterize asset business. Others, the liability business and intermediate business are characterized by deposits and non-interest incomes.

Additionally, the non-performing loans are generated when loans are not paid back, which is a post process variable that could not be strongly disposable. We believe that non-performing loans can only be eliminated together with loans, subject to technical restrictions. Therefore, we consider non-performing loans as undesirable outputs with the weak disposability.

\subsection{Data Collection and Pre-Procession}

In this paper, the M\&A events are collected from Wind Database according to the conditions: (i) Transaction buyer (M\&A bank): Banks on Shenzhen-Shanghai stock exchange; (ii) The latest disclosure time/completion time (M\&A year): 2004-2018; (iii) State of transaction progress: Completed. For accessibility and rationality of data, we further dealt with the list of M\&A events. First, the M\&A events of branches or subsidiaries are regarded as the events of their parent company. Second, the M\&A events of the company before being merged are regarded as the events of the company after merger. For example, the M\&A activities of Shenzhen Development Bank and Shenzhen Commercial Bank, which are merged by former Ping An Bank, are both regarded as activities of Ping An Bank. Third, eliminating misclassified non-bank companies, i.e., China Merchants Securities Co., Ltd. Ultimately, 74 M\&A events are selected, involving $14 \mathrm{M} \& \mathrm{~A}$ banks across 15 years. Brief information of 30 random items in 
total M\&A events follows in Appendix A. The 14 M\&A banks involving five state-owned banks and 9 other banks (joint-stock commercial banks and city commercial banks), referring to the categories of banking institutions by CBIRC. We measure the performance of these M\&A banks during 2004-2019 for the delayed feedback. All the data are collected in the annual financial reports of each M\&A bank exposed in Wind and iFinD database.

Though we try our best to get a complete dataset, there are missing data still. Besides data of CEB and JSBC in 2004 are lacked, several items also miss data. Data pre-processing is required to fill the blank and several factors are taken into account that (i) time series is one of the data characters, (ii) person-level missingness ${ }^{[66]}$ exits in two items, and (iii) positive number is asked for in the calculation of DEA model. Therefore, exponential regression of interpolation method is applied, which is the traditional method to predict values greater than zero. Data pre-processing steps follows.

\section{Step 1: Calculating "Non-interest income".}

The non-interest incomes of the BOB, ABC and JSBC are estimated by subtracting interest incomes from operating incomes of the current year, which exclude the two person-level missed items. The estimated result of BOB in 2004 is negative, so we put it into Step 2.

\section{Step 2: Estimating data of other indicators.}

Organizing data by dividing banks into 14 groups to fit the exponential regression model separately in SPSS 22.0. The model takes year as the independent variable, and the indicators estimated as dependent variables. We test the values of adjusted $R^{2}$ listed in Table 3 , which represent the fitting proportion of the variance for the estimated indicator that's explained by year (time changes). The $R^{2}$ values are all greater than 0.5 and almost near to 1 . It means the fitting results are reliable and then interpolate the estimated values.

Table 3 Adjusted $R^{2}$ values

\begin{tabular}{lccccccc}
\hline & BOB & JSBC & SPABANK & ICBC & CEB & ABC & BOC \\
\hline$x_{1}$ & 0.9 & 0.94 & & 0.95 & & \\
$x_{2}$ & 0.98 & & & 0.96 & & \\
$z_{1}$ & 0.96 & & & 0.96 & 0.96 & \\
$y_{1}$ & & 0.96 & & & 0.91 & & \\
$y_{2}$ & 0.92 & 0.7 & & & 0.94 & & \\
$y_{3}$ & & 0.98 & & & 0.99 & 0.98 & \\
$y_{4}$ & 0.95 & & 0.96 & 0.91 & 0.99 & 0.68 \\
$u_{1}$ & 0.95 & & & 0.55 & 0 & \\
\hline
\end{tabular}

\section{Step 3: Adjusting special data.}

The coefficient of data group is 0 , on behalf of the inappropriacy to interpolate the missing data in 2004 and 2005. Through observation, we find the values almost remained flat over 2006 to 2012. Therefore, the mean value of JSBC's financial investment over the seven years is selected for interpolation.

The "Non-performing loan" of $\mathrm{ABC}$ also fails to be estimated for degree of fitting is 0 , because the values fluctuate up and down. So, the average value of ABC's acquired data about 
non-performing loans is taken as the interpolation value.

Eventually, we complete the dataset and describe it in Table 4.

Table 4 Data description of complete dataset

\begin{tabular}{lcccccccc}
\hline & $x_{1}$ & $x_{2}$ & $z_{1}$ & $y_{1}$ & $y_{2}$ & $y_{3}$ & $y_{4}$ & $u_{1}$ \\
\hline Mean & 5.09 & 591.08 & 428.68 & 311.5 & 120.83 & 22.64 & 4.21 & 5.72 \\
SD & 5.34 & 658.84 & 498.68 & 360.78 & 157.82 & 23.67 & 5.15 & 9.23 \\
Min & 0.11 & 10.9 & 11.37 & 6.91 & 0.57 & 0.43 & 0.01 & 0.12 \\
Max & 19.91 & 3010.94 & 2297.77 & 1676.13 & 764.71 & 103.82 & 24.82 & 81.89 \\
Sum & 224 & 224 & 224 & 224 & 224 & 224 & 224 & 224 \\
\hline
\end{tabular}

\subsection{Results and Analysis}

\subsubsection{Efficiency Evaluation}

Appendix B lists the efficiency scores from applying the proposed model based on the PPS specified in formula (11). To obtain the general performance of each bank, we calculate average scores (column Ave.) by line, and rank the banks (column Rank) according to the overall and two stages' average scores respectively. Others, we emphasize the M\&A events' years and state-owned banks in bold for the sake of further analysis. Concentrating on the M\&A events, the overall efficiency scores are between 0.11 and 0.87 , which tells the reason for M\&A Inefficiency. Then we calculate and plot the annual average efficiency score line chart in Figure 2 to make a dynamic analysis on the average performance of banking.

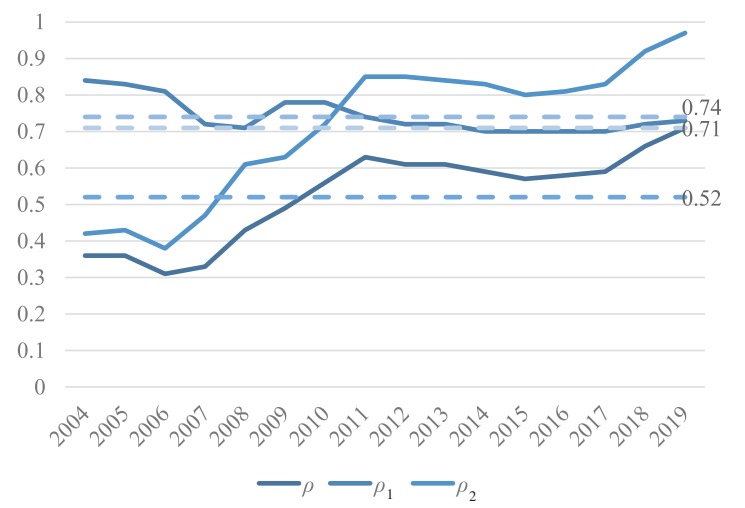

Figure 2 Trends of average efficiency scores across years

The results in Appendix B suggest that the efficient DMUs were BCM in 2004 and CMB in 2019, two of 224 DMUs. Based on the column Ave., the top-ranked banks over average are CMB, CNCB, SDPB, JSBC (without state-owned banks), the banks with more advanced stage 1 than average are CMB, JSBC, CNCB, ABC, BCM, SDPB, and the banks with advanced stage 2 are ICBC, CEB, CMB, CNCB, SDPB, CIB and BOB. After being decomposed into two stages, CMB performed best in both whole system and stage 1, while ICBC performed best in stage 2. In general, we can observe the efficient stage is almost the second stage (9 efficient stage 1 and 46 efficient stage 2). And all the first stage's efficiency scores are higher than 0.5 
throughout the measurement periods, while the second stage's efficiency scores are higher than 0.5 from 2014. The two observations tell the story that the benchmarks in stage 2 are more than ones in stage 1 and the banks with low average scores have been improved. It manifests that banks' accumulation process performs well continuously in total while obvious learning phenomenon arose in earning process.

In Figure 2, the reference lines come from the aggregated average values of all banks. We observe the average overall performance is improving in general, besides there are turning points at 2006, 2011, 2015. Considering the two-stage structure, the performance of the earning process changes in roughly the same trend of overall performance, while the accumulation process changes almost in reverse.

\subsubsection{Global Malmquist Index}

The results on GMI of whole system and stages from the $t$ th to $(t+1)$ th year is summarized in Appendix C. None of the banks increase or decrease their efficiency continuously year-by-year, which means all M\&A banks' performance fluctuates by years. The last four columns in the table report two pieces of information. First, the cumulative GMIs in 2019, simply generated by the data in 2004 and 2019. It ignores the performance of intermediate periods. 12 banks' cumulative GMIs of whole system and of stage 2 are greater than 1, excluding ICBC and BCM; 2 banks' GMIs of stage 1 are greater than 1, CNCB and SDPB. These indicate that most M\&A banks' productivities of whole system and earning process have been improved from 2004 to 2019 , but the most of accumulation process have been declined. Second, the average scores of annual productivity changes for each bank and the two stages are showed. The scores reflect the average fluctuation of efficiency values across years. The similar conclusion came out that M\&A banks' productivities on whole system and earning process improved, while most M\&A banks' accumulation process regress on average. This finding is approximately consistent with the implications expressed in Figure 2 as mentioned above.

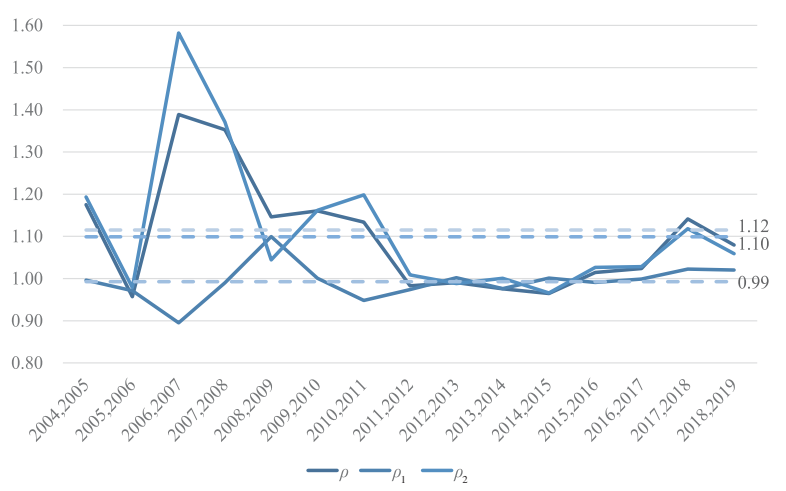

Figure 3 Trends of average GMI scores across years

To explore the trend of banking productivity, we calculate and plot the annual average GMI line chart in Figure 3. It explicitly demonstrates that, the GMIs of the whole system and stage 2 fluctuate greatly around 1.1, and they have a high degree of coincidence; the GMI of stage 1 fluctuates around 1.0 relatively steadily. It indicates that the productivities of whole 
system and earning process changes at a high range and speed, yet the accumulation process productivity has changed steadily but not improved significantly. Frequency calculation but not showed makes things clear that, $85 \%$ productivities of stage 2 and whole system ascend or descend at the same time (joint progress and regression), while only $55 \%$ of the stage 1. Then we can conclude that the earning process is more vital to the whole system than the accumulation process. Specifically, the GMI peak points of whole system and stage 2 and the valley point of stage 1 appears simultaneously in the same period from 2006 to 2007. Associate to the $0 \mathrm{M} \& \mathrm{~A}$ event in 2005, the year before 2006, these special points could be caused by the instability of M\&A events. It's a sign that in short terms, the M\&A activities could promote the overall production system and earning process of banking, but have a negative impact on the accumulation process.

Concentrating on the M\&A events, the bold data in Appendix $\mathrm{C}$ illustrate the impacts of M\&A events in the $t$ th year on the efficiency of banks in the year after that. There are 2 banks BCM, CNCB with overall GMI greater than 1. Likewise, for stage 1, the GMIs of CNCB are greater than 1, and ICBC and BCM for stage 2. The improvement effect by M\&A on the overall production system and earning process performance of ICBC and BCM (two state-owned banks) and on the accumulation process of CNBC is revealed. From the view of time, GMI of M\&A events in 2017 is greater than 1, while in 2011, 2014 and 2016 is under 1. Namely, in the past 16 years, banks benefit from M\&A in 2017 but the negative effect on banks arose in 2011, 2014 and 2016.

Appendix D reports the decomposition of GMIs in whole system, stage 1 and stage 2 to EC and TC. The table illustrates the cumulative changes by 2019 from 2004 in column 2004, 2009 and the average change of productivity changes every year in column Ave. Firstly, we analyze TC of all M\&A banks. The technology level of overall production system and of stage 2 cumulates to $214 \%$ and $252 \%$ improvement, but of stage 1 declined by $11 \%$. Additionally, TC values in column Ave.ascend in whole system and stage 2 by an average of $11 \%$ and $12 \%$, but descend in stage 1. Both observations above demonstrate that a banks performance of overall technology has been significantly driven by profit earning technology. However, different situation occurs in EC. The cumulative efficiency scores in 2019 of both overall banks and their stages declined by less than $5 \%$, compared with 2004. The average EC values in whole system and stage 1 ascend by less than $1 \%$ and $6 \%$, but the average value of stage 1 descend by less than $2 \%$. Then we come to the conclusion that the EC relationship of whole system and stages is inconspicuous because of the unobvious EC. Specifically, the state-owned banks hadn't performed better than other banks in either EC or TC during 2004 to 2019.

\subsubsection{Classification Analysis}

Banks initiate M\&A for their inefficient performance, and the promotion of M\&A is confirmed. The influences on specific process should be classified. From the observation above, M\&A could promote the overall performance and the earning process of banks, but have a negative impact on the accumulation process. While the promotion may come from the obvious learning phenomenon in earning process. We conclude that the M\&A plan could be decided on the specific process according to the bank's industry-leading position and the technology or 
efficiency should be learned principally. Thus, we classify the banks as follows.

Certain bank may lead in some aspects. For stages, the excellent performance of certain stage reflects the bank's dominant position in this process, while upgrade the other stage. In other words, preparing for M\&A needs more attention on deficient process. On the contrary, it is helpful for banks to make decision on M\&A following the advanced characteristic of banks' progress to develop. EC reflects a bank's change of efficiency level, and TC value means the extent of bank's technical progress but the regress of technology when lower than 1 .

Thus, we organize the M\&A banks in two perspectives. In the first perspective, we define the banks' dominant positions according to whether the efficiency value (from Ave. column in Appendix B) of accumulation process and earning process is higher than average (the values of average reference line of both stages in Figure $3-0.74$ and 0.71 ). In the other perspective, we define the characteristics of banks' progress based on the relationship between 1 magnitude and scores of TC and EC (from Ave. columns in Appendix D). Noted that it's not convinced for a bank's overall level to make Malmquist index from 2004 to 2019 as representative, accounting of the only effect by the performance in these two years. The categories results are illustrated in Figure 4, with elucidation as follows.
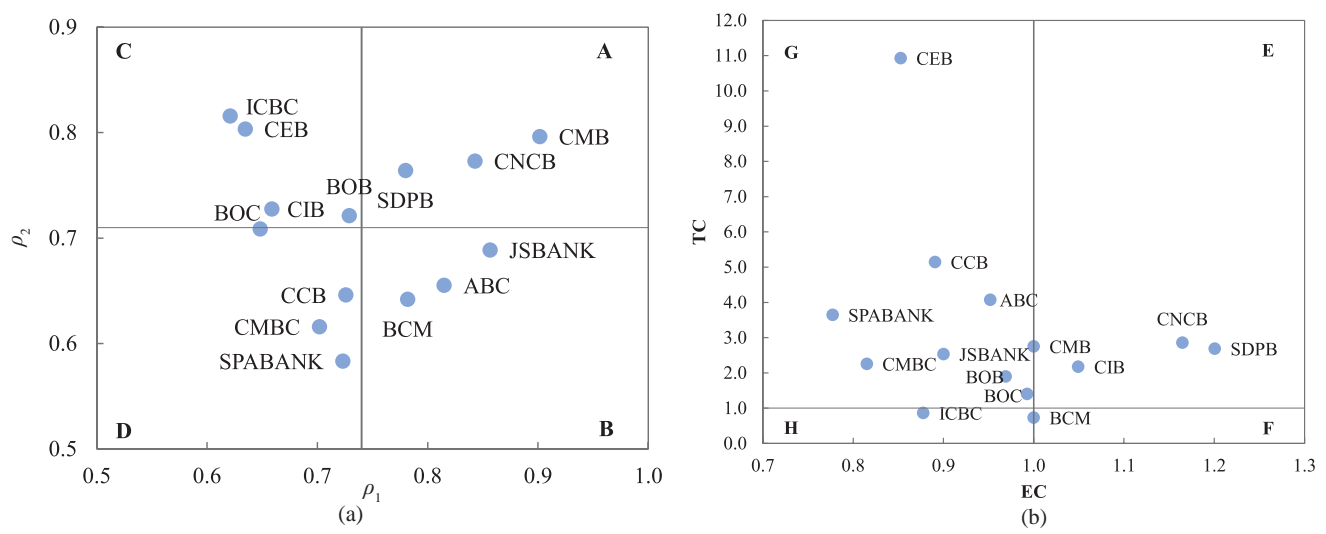

Figure 4 Categories of (a) advanced process and (b) change of technology and efficiency for 14 M\&A banks in China

\section{(i) Dominant position}

A. Competitive leading banks. They are banks with a higher level of accumulation process and earning process above average. In total, there are three banks, namely CMB, $\mathrm{CNCB}$ and SDPB, who attain the top three in overall production system performance. They set benchmarks for other M\&A banks to try comprehensive development in two stages process and then get the outstanding system. Banks belonging to this category should maintain their process competition advantage to follow market trend and expand M\&A to be pioneer.

B./C. Accumulation/Earning process leading banks. The accumulation/earning process of these banks perform better than average of M\&A banks, but earning/accumulation process perform worse. JSBC, ABC, BCM are accumulation process leading banks and ICBC, $\mathrm{CEB}, \mathrm{CIB}, \mathrm{BOB}$ are earning process leading banks. They should balance the M\&A goal between taking their own process advantage and making up the backward one by M\&A. 
D. Low-competitive banks. They are banks with lower performance of two individual stages. Banks BOC, CCB, CMBC, SPABANK have a lower performance of both stages than average of M\&A banks. Clearly, actions are required to absorb vitality of both accumulation and earning from target company in M\&A.

(ii) Characteristic of banks' progress

E. Banks with comprehensive development. Their technology and efficiency level both improved in average. They are CIB, CMB, CNCB, SDPB. This indicates that they have comprehensive development capacity to absorb the advanced technology and efficiency management from the M\&A object. A further consideration involving M\&A plan is vital.

F. Banks with technical progress. Technology level of them would be gradually increasing. Only BCM with greater TC than 1 but lower EC than 1, which signifying technical progress and efficiency decline. It could intensify through learning technology by M\&A. However, when they have got leading position, the ability to improve efficiency is urgently required.

G. Banks with efficiency progress. They perform well in efficiency progress, but get technology regression. ABC, JSBC, CMBC, CCB, SPABANK, BOC, BOB and CEB belong to this category. Namely, they could enhance themselves by following growing trend of efficiency and enhance the ability to improve technology growth when they are leading.

H. Banks with inadequate development. These banks regress in both technology and efficiency, denoting inadequate development. ICBC satisfy the characteristic. It should absorb advanced technology during $\mathrm{M} \& \mathrm{~A}$, and learn for pioneers in efficiency.

In conclusion, 7 portfolio categories covered by the 14 M\&A banks are summarized as follows. Combination of letters in column types represents banks of certain dominant position with certain characteristic. For example, (B, F) means accumulation process leading banks with technical progress.

Table 5 Categories summarization of 14 M\&A banks

\begin{tabular}{cc}
\hline Types & Banks \\
\hline$(\mathrm{A}, \mathrm{E})$ & $\mathrm{CMB}, \mathrm{CNCB}, \mathrm{SDPB}$ \\
$(\mathrm{B}, \mathrm{F})$ & $\mathrm{BCM}$ \\
$(\mathrm{B}, \mathrm{G})$ & $\mathrm{ABC}, \mathrm{JSBC}$ \\
$(\mathrm{C}, \mathrm{E})$ & $\mathrm{CIB}$ \\
$(\mathrm{C}, \mathrm{G})$ & $\mathrm{BOC}, \mathrm{BOB}, \mathrm{CEB}$ \\
$(\mathrm{C}, \mathrm{H})$ & $\mathrm{ICBC}$ \\
$(\mathrm{D}, \mathrm{G})$ & $\mathrm{CCB}, \mathrm{CMBC}, \mathrm{SPABANK}$ \\
\hline
\end{tabular}

\section{Discussion}

Since the government of China (GOC) decided to implement the shareholding reform of commercial banks at the end of 2003. The number of M\&A events in Figure 5 reveals that the wave of M\&A in China's banking appeared in the period of 2006-2010 and reached the peak in 2008. State-owned banks are main entities of economic reforms, the M\&A events of which reached high proportion. However, as mentioned above, the reform hasn't given obvious advantage to these state-owned banks over other M\&A banks in neither average performance 
nor dynamic productivity changes. There are two reasons. First, the large scale of them lead to the inefficiency. State-owned banks accounts for $39.1 \%$ assets of banking financial institutions as of December 2019 (CBIRC). Besides, it takes time to influence these large-scale banks by M\&A. It has been revealed that the large scale could extend the time to work out ${ }^{[67]}$.

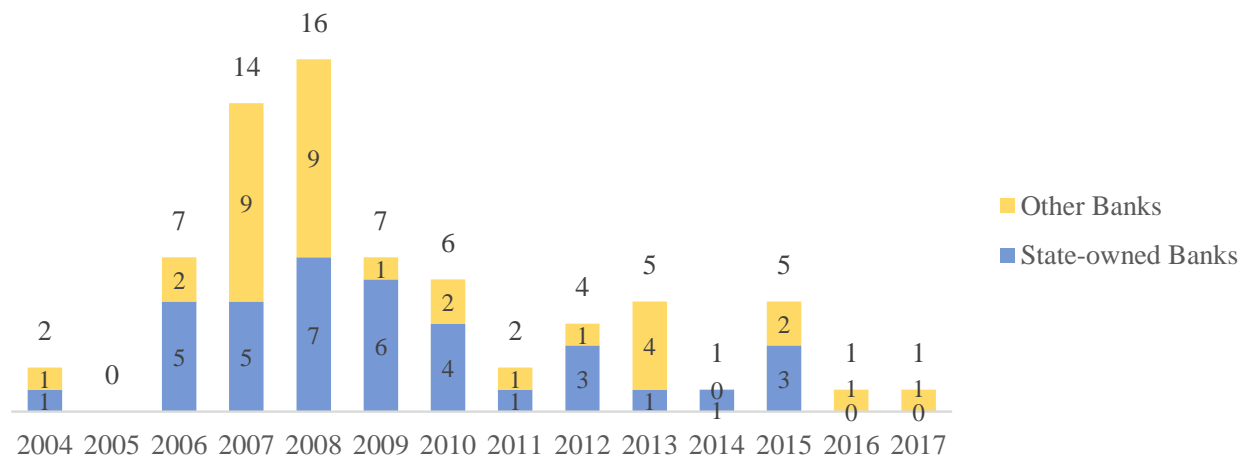

Figure 5 Amount of M\&A events

From 2007 to 2009, a well-known global financial crisis (GFC) broke out. It began from 2006 with the subprime mortgage crisis in the UK and the US. The financial institutions suffered a huge impact ${ }^{[68-73]}$. However, it seems that the overall productivity change of M\&A banks in China are immune to the negative impact of GFC. Their productivity achieved the largest increase from 2006 to 2007, and increase continuously from 2007 to 2011. The productivity change of their earning process was the same, but the accumulation process was more likely suffered. The productivity of accumulation process reached the greatest decline in 2007, then rebounded and kept stable after 2011. Facing GFC, the GOC launched some monetary policies from 2008 to stabilize the market, e.g., cutting the benchmark interest rate for loan and RMB deposit reserve rate. These policies worked as implementation. Since 2008, the efficiency of the accumulation process has increased, already below average. The efficiencies of whole system and earning process have improved and stayed above average since 2010.

We ascribe the observations above to two phenomena. First, M\&A has a significant shortterm effect of improving banks' profit earning ability. Just during the year of subprime mortgage crisis before GFC, China's banking economy achieved the potential for rapid development through the early stage of M\&A wave. And in 2009, as GFC gradually went by, China's economy has warmed up gradually. After that, the accumulation process of M\&A banks stepped into a stable stage, while the efficiency of whole system and earning process continued to improve and remained at a high level. Second, the deposit growth of banking slowed down between 2006 and 2008 as shown in Figure 6. It leads to the decrease of the efficiency of the accumulation process and the increase of the efficiency of earning process. The slowdown is the result of China's regulatory policies that has worked to stabilize bank deposits, reduce interest income in short term and simulate loan and investment business.

As the classifications in Section 3, different M\&A banks need different M\&A directions. $\mathrm{CMB}, \mathrm{CNCB}$ and SDPB need a further M\&A plan to maintain prior status. BCM could take advantage of rapid efficiency changes to learn from companies who lead in profitability through high efficiency. Likewise, ABC and JSBC could concentrate the companies performing better 
in accumulation with advance technology. While CIB need to improve accumulation process through M\&A. BOC, BOB, CEB could merge or acquire the better-performing companies in accumulating through advanced technology. ICBC should survey the accumulating better company with comprehensive development in both efficiency and technology. CCB, CMBC, SPABANK could merge or acquire company with comprehensive development and develop their own dominant stage process.

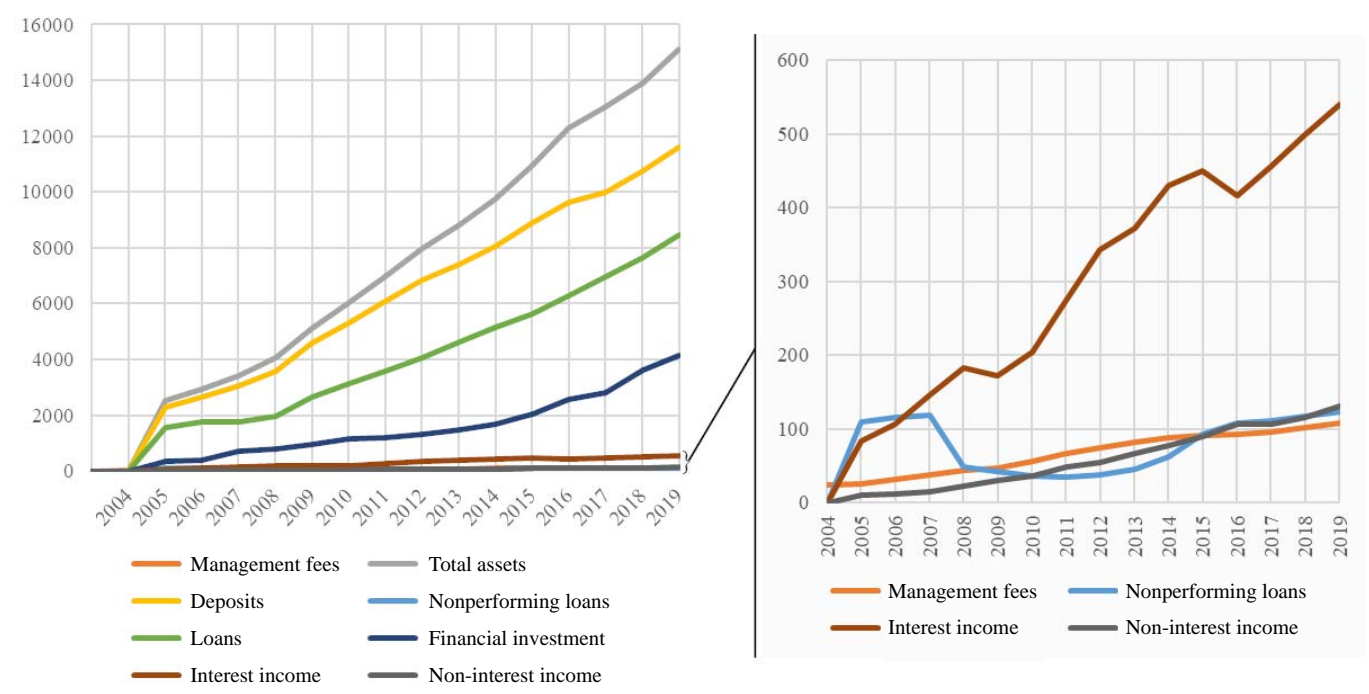

Figure 6 Banking indicators statistics over time

\section{Conclusion}

Banks in China have stepped into a new stage of reform since $2003^{[74]}$. The reform has verified to improve the efficiency of banks and optimize the business environment. M\&A are important parts of the reform process, from which China's banking industry has gained great potential for performance development. During GFC, the positive effect of M\&A on the efficiency of banks was confirmed once again. Thus, after the measurement of productivity change, we suggest an M\&A plan for M\&A banks involving the process need to improve and the trend they could adopt.

This paper constructs a two-stage SBM model and applies to measure the productivity change of China's banks who have completed M\&A during 2004-2018. The SBM model is under the weak disposability assumption of undesirable outputs. We arrange the variables of bank production system with two-stage structure in previous researches. Eventually, the production the framework is defined as inputs (management fees and total assets), intermediate variable (deposits), desirable outputs (interest income, non-interest income, loans and financial investment) and undesirable output (non-performing loans), and the production system is divided into accumulation process and earning process. In addition, the application based on the improved SBM model utilizes GMI to evaluate the productivity change of M\&A banks from 2004 to 2019.

The main empirical results of this study tell the story of M\&A in China's banking over the last 15 years. In the beginning, some inefficient banks came to the decision of M\&A to 
improve their efficiency. From the efficiency measurement and GMI, M\&A indeed worked in short term but exerted different influence on accumulation process and earning process of banks. In general, the M\&A activities promoted the overall production process and earning process of banks, but the accumulation process stayed steady. The learning phenomenon just arose in earning process accounts for the difference. Furthermore, the decomposition of GMI exposed the different influence of M\&A on the feature of productivity change in each process. In earning process, the EC improved while a negative signal presented in the TC. While in accumulation process, both EC and TC are regressive.

We category the banks according to their dominant position and characteristic of progress. From dominant position, we classify the banks into four groups, A-D. Namely, the first category group are competitive leading banks (group A), accumulation/earning process leading banks (group B/C) and low-competitive banks (group D). From characteristic of progress, we classify the banks into groups E-H. They are banks with comprehensive development (group E), banks with technology/efficiency progress (group F/G), and banks with inadequate development (group H). Different group of banks should consider different M\&A plan to develop, e.g., banks in group B and group G meanwhile should learn from companies with more advanced profitability (earning ability) in terms of technology. Furthermore, in China's financial system, state-owned banks possess a prominent position. However, their efficiency performance is not outstanding, and the short-term effect of $M \& A$ on them is not significant. Therefore, for further development, the five state-owned M\&A banks should consider a long-term M\&A plans.

With the rapid development of China's banking, the wave of M\&A in China's banking has appeared, which bring continuous vitality. Through the M\&A activities of a certain bank, different processes perform quite differently in productivity change. Learning phenomenon in M\&A is used to address the unbalanced development. Dynamic analysis reveals the feature of productivity change by TC and EC that expose the direction to learn. Accordingly, it is important for a bank to promote performance by accurate M\&A plan to make up the backward process through utilizing advanced change.

\section{References}

[1] Sufian F. Determinants of bank profitability in a developing economy: Empirical evidence from the China banking sector. Journal of Asia-Pacific Business, 2009, 10(4): 281-307.

[2] Wang K, Huang W, Wu J, et al. Efficiency measures of the Chinese commercial banking system using an additive two-stage DEA. Omega, 2014, 44: 5-20.

[3] Sathishkumar T, Tamby P N A. Effect of mergers and acquisitions on performance of enterprise value. MUDRA: Journal of Finance and Accounting, 2018, 5(2): 60-69.

[4] Bena J, Li K. Corporate innovations and mergers and acquisitions. The Journal of Finance, 2014, 69(5): 1923-1960.

[5] Blanco-Oliver A. Banking reforms and bank efficiency: Evidence for the collapse of Spanish savings banks. International Review of Economics and Finance, 2021, 74: 334-347.

[6] Zhu Q, Li X, Li F, et al. Data-driven approach to find the best partner for merger and acquisitions in banking industry. Industrial Management \& Data Systems, 2020, 121(4): 879-893.

[7] Lee C C, Li X, Yu C H, et al. Does fintech innovation improve bank efficiency? Evidence from China's banking industry. International Review of Economics \& Finance, 2021, 74: 468-483.

[8] Du K, Sim N. Mergers, acquisitions, and bank efficiency: Cross-country evidence from emerging markets. Research in International Business and Finance, 2016, 36: 499-510. 
[9] Zarei M, Alambeigi A, Zarei B, et al. The effects of mergers and acquisitions (M\&As) on bank performance and entrepreneurial orientation (EO). Springer International Publishing, 2017: 361-375.

[10] Vander Vennet R. Cost and profit dynamics in financial conglomerates and universal banks in Europe. Journal of Money, Credit and Banking, Ohio State University, 2002, 34(1): 254-282.

[11] Houston J F, James C M, Ryngaert M D. Where do merger gains come from? Bank mergers from the perspective of insiders and outsiders. Journal of Financial Economics, 2001, 60(23): 285-331.

[12] Rezitis A N. Efficiency and productivity effects of bank mergers: Evidence from the Greek banking industry. Economic Modelling, 2008, 25(2): 236-254.

[13] Emrouznejad A, Yang G L. A survey and analysis of the first 40 years of scholarly literature in DEA: 1978-2016. Socio-Economic Planning Sciences, 2017, 61: 4-8.

[14] Xu G, Zhou Z. Assessing the efficiency of financial supply chain for Chinese commercial banks: A two-stage AR-DEA model. Industrial Management \& Data Systems, 2020, 121(4): 894-920.

[15] Cook W D, Zhu J, Chai D. Data envelopment analysis: A Handbook of Modeling Internal Structure and Networks. Springer, 2014.

[16] Xi W, Cheng X R. The difference of capital input and productivity in service industries: Based on four stages Bootstrap-DEA model. Journal of Systems Science and Information, 2018, 6(4): 320-335.

[17] Wanke P, Maredza A, Gupta R. Merger and acquisitions in South African banking: A network DEA model. Research in International Business and Finance, 2017, 41: 362-375.

[18] Lin B, Song D, Liu Z Y. A model of aircraft support concept evaluation based on DEA and PCA. Journal of Systems Science and Information, 2018, 6(6): 563-576.

[19] Charnes A, Cooper W W, Rhodes E. Measuring the efficiency of decision making units. North-Holland, 1978, 2(6): 429-444.

[20] Banker R D, Charnes A, Cooper W W. Some models for estimating technical and scale inefficiencies in data envelopment analysis. Management Science, 1984, 30(9): 1078-1092.

[21] Tone K. A slacks-based measure of efficiency in data envelopment analysis. European Journal of Operational Research, 2001, 130(3): 498-509.

[22] Avkiran N K. The evidence on efficiency gains: The role of mergers and the benefits to the public. Journal of Banking and Finance, 1999, 23(7): 991-1013.

[23] Sufian F. Mergers and acquisitions in the Malaysian banking industry: Technical and scale efficiency effects. International Journal of Financial Services Management, 2007, 2(4): 304-326.

[24] Castelli L, Pesenti R, Ukovich W. DEA-like models for the efficiency evaluation of hierarchically structured units. European Journal of Operational Research, 2004, 154(2): 465-476.

[25] Cook W D, Zhu J, Bi G, et al. Network DEA: Additive efficiency decomposition. European Journal of Operational Research, 2010, 207(2): 1122-1129.

[26] Shahroudi K, Taleghani M, Mohammadi G. Application of two-stage DEA technique for efficiencies measuring of private insurance companies in Iran. International Journal of Applied Operational Research, 2011, 1(3): 91-105.

[27] Xie J, Zhu X, Liang L. A multiplicative method for estimating the potential gains from two-stage production system mergers. Annals of Operations Research, Springer, 2020, 288(1): 475-493.

[28] An Q, Chen $\mathrm{H}, \mathrm{Wu}$ J, et al. Measuring slacks-based efficiency for commercial banks in China by using a two-stage DEA model with undesirable output. Annals of Operations Research, 2015, 235(1): 13-25.

[29] Pan W, Huang L, Zhao L. An integrated DEA model allowing decomposition of eco-efficiency: A case study of China. Journal of Systems Science and Information, 2017, 5(5): 473-488.

[30] Shephard R W. Theory of cost and production functions. Princeton: Princeton University Press, 1971.

[31] Fre R, Grosskopf S, Roos P. Productivity and quality changes in Swedish pharmacies. International Journal of Production Economics, 1995, 39(12): 137-144.

[32] Chen C H, Liu H H, Tang L J, et al. A range adjusted measure of super-efficiency in integer-valued data envelopment analysis with undesirable outputs. Journal of Systems Science and Information, 2021, 9(4): 378-398.

[33] An Q, Wu Q, Li J, et al. Environmental efficiency evaluation for Xiangjiang river basin cities based on an improved SBM model and Global Malmquist index. Energy Economics, 2019, 81: 95-103.

[34] Zhu W, Zhu Y, Yu Y. China's regional environmental efficiency evaluation: A dynamic analysis with biennial Malmquist productivity index based on common weights. Environmental Science and Pollution 
Research, 2020, 27(32): 39726-39741.

[35] Li N, Jiang Y, Yu Z, et al. Analysis of agriculture total-factor energy efficiency in China based on DEA and Malmquist indices. Energy Procedia, 2017, 142: 2397-2402.

[36] Pan W T, Zhuang M E, Zhou Y Y, et al. Research on sustainable development and efficiency of China's EAgriculture based on a data envelopment analysis-Malmquist model. Technological Forecasting and Social Change, 2021, 162: 120298.

[37] Mavi N K, Mavi R K. Energy and environmental efficiency of OECD countries in the context of the circular economy: Common weight analysis for malmquist productivity index. Journal of Environmental Management, 2019, 247: 651-661.

[38] Pacagnella A C, Hollaender P S, Mazzanati G V, et al. Infrastructure and flight consolidation efficiency of public and private brazilian international airports: A two-stage DEA and Malmquist index approach. Journal of Advanced Transportation, 2020, 2020: 2464869.

[39] Luo Q, Miao C, Sun L, et al. Efficiency evaluation of green technology innovation of China's strategic emerging industries: An empirical analysis based on Malmquist-data envelopment analysis index. Journal of Cleaner Production, 2019, 238: 117782.

[40] Pastor J T, Lovell C A K. A global Malmquist productivity index. Economics Letters, 2005, 88(2): $266-271$.

[41] Tone K, Tsutsui M. Network DEA: A slacks-based measure approach. European Journal of Operational Research, 2009, 197(1): 243-252.

[42] Kuosmanen T. Weak disposability in nonparametric production analysis with undesirable outputs. American Journal of Agricultural Economics, 2005, 87(4): 1077-1082.

[43] Wanke P, Barros C P, Azad M A K, et al. The development of the mozambican banking sector and strategic fit of mergers and acquisitions: A two-stage DEA approach. African Development Review, 2016, 28(4): 444-461.

[44] Wang C H, Gopal R D, Zionts S. Use of data envelopment analysis in assessing information technology impact on firm performance. Annals of Operations Research, 1997, 73: 191-213.

[45] Zha Y, Liang N, Wu M, et al. Efficiency evaluation of banks in China: A dynamic two-stage slacks-based measure approach. Omega, 2016, 60(4): 60-72.

[46] Benston G J. Branch banking and economics of scale. The Journal of Finance, 1965, 20(2): 312-331.

[47] Glass J C, McKillop D G, Rasaratnam S. Irish credit unions: Investigating performance determinants and the opportunity cost of regulatory compliance. Journal of Banking and Finance, 2010, 34(1): 67-76.

[48] Koiov K. Two-stage DEA: An application in banking. Scientific and Technical Revolution: Yesterday, Today and Tomorrow, 2020: 1483-1517.

[49] Titko J, Stankeviien J, Lce N. Measuring bank efficiency: DEA application. Technological and Economic Development of Economy, 2014, 20(4): 739-757.

[50] Sealey C W, Lindley J T. Inputs, outpus, and a theory of production and cost at depository financial institutions. The Journal of Finance, 1977, 32(4): 1251-1266.

[51] Ahn H, Le M H. An insight into the specification of the input-output set for DEA-based bank efficiency measurement. Management Review Quarterly, 2014, 64: 3-37.

[52] Thagunna K S, Poudel S. Measuring bank performance of Nepali banks: A data envelopment analysis (DEA) perspective. International Journal of Economics and Financial Issues, 2013, 3(1): 54-65.

[53] Holod D, Lewis H F. Resolving the deposit dilemma: A new DEA bank efficiency model. Journal of Banking and Finance, 2011, 35(11): 2801-2810.

[54] Avkiran N K. Association of DEA super-efficiency estimates with financial ratios: Investigating the case for Chinese banks. Omega, 2011, 39(3): 323-334.

[55] Partovi E, Matousek R. Bank efficiency and non-performing loans: Evidence from Turkey. Research in International Business and Finance, 2019, 48: 287-309.

[56] Peng Y H, Wang K. Cost efficiency and the effect of mergers on the Taiwanese banking industry. Service Industries Journal, 2004, 24(4): 21-29.

[57] Ying Z, Fangfang T A N. Study on the development of the intermediate business of commercial banks in China. Canadian Social Science, 2015, 11(6): 104-108.

[58] Shi X, Li Y, Emrouznejad A, et al. Estimation of potential gains from bank mergers: A novel two-stage cost efficiency DEA model. Journal of the Operational Research Society, 2017, 68(9): 1045-1055.

[59] Liu W, Zhou Z, Ma C, et al. Two-stage DEA models with undesirable input-intermediate-outputs. Omega, 
2015, 56: 74-77.

[60] Akther S, Fukuyama H, Weber W L. Estimating two-stage network Slacks-based inefficiency: An application to Bangladesh banking. Omega, 2013, 41(1): 88-96.

[61] Fukuyama H, Matousek R. Efficiency of Turkish banking: Two-stage network system. Variable returns to scale model. Journal of International Financial Markets, Institutions and Money, 2011, 21(1): 75-81.

[62] Fukuyama H, Weber W L. A slacks-based inefficiency measure for a two-stage system with bad outputs. Omega, 2010, 38(5): 398-409.

[63] Lo S F, Lu W M. An integrated performance evaluation of financial holding companies in Taiwan. European Journal of Operational Research, 2009, 198(1): 341-350.

[64] Luo X. Evaluating the profitability and marketability efficiency of large banks: An application of data envelopment analysis. Journal of Business Research, 2003, 56(8): 627-635.

[65] Seiford L M, Zhu J. Profitability and marketability of the top 55 U.S. commercial banks. Management Science, 1999, 45(9): 1270-1288.

[66] Newman D A. Missing data: Five practical guidelines. Organizational Research Methods, 2014, 17(4): $372-411$.

[67] Liang H X, Jian J M, Jiang H A, et al. Cross-border mergers and acquisitions of China's large commercial banks and their impact on efficiency. Finance Forum, 2011, 12: 20-36 (in Chinese).

[68] Alexakis C, Izzeldin M, Johnes J, et al. Performance and productivity in Islamic and conventional banks: Evidence from the global financial crisis. Economic Modelling, 2019, 79: 1-4.

[69] Chen Z, Matousek R, Wanke P. Chinese bank efficiency during the global financial crisis: A combined approach using satisficing DEA and support vector machines. North American Journal of Economics and Finance, 2018, 43: 71-86.

[70] Claessens S, Van Horen N. The impact of the global financial crisis on banking globalization. IMF Economic Review, 2015, 63(4): 868-918.

[71] Ellaboudy S. The global financial crisis: Economic impact on GCC countries and policy implications. International Research Journal of Finance and Economics, 2010(41): 180-193.

[72] Kasim S, Majid M. Impact of financial shocks on Islamic banks: Malaysian evidence during 1997 to 2007 financial crisis. International Journal of Islamic and Middle Eastern Finance and Management, 2010, 3(4): 291-305.

[73] Smolo E, Mirakhor A. The global financial crisis and its implications for the Islamic financial industry. International Journal of Islamic and Middle Eastern Finance and Management, 2010, 3(4): 372-385.

[74] Li P, Zeng Y, Zhu X L. The impact of China's banking reform on the efficiency change of Chinese banks. Chinese Journal of Management Science, 2013, 16(8): 47-53 (in Chinese). 


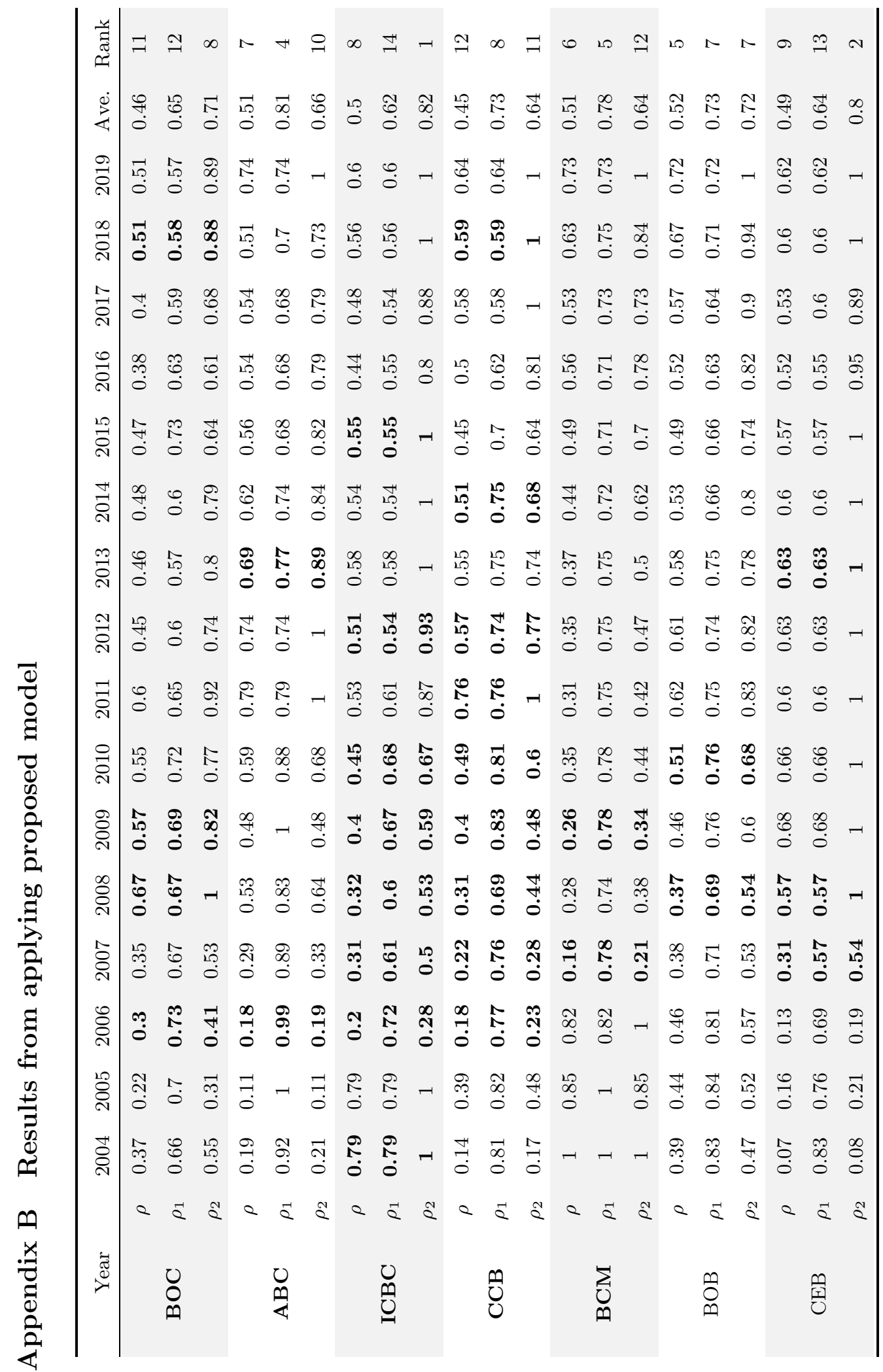




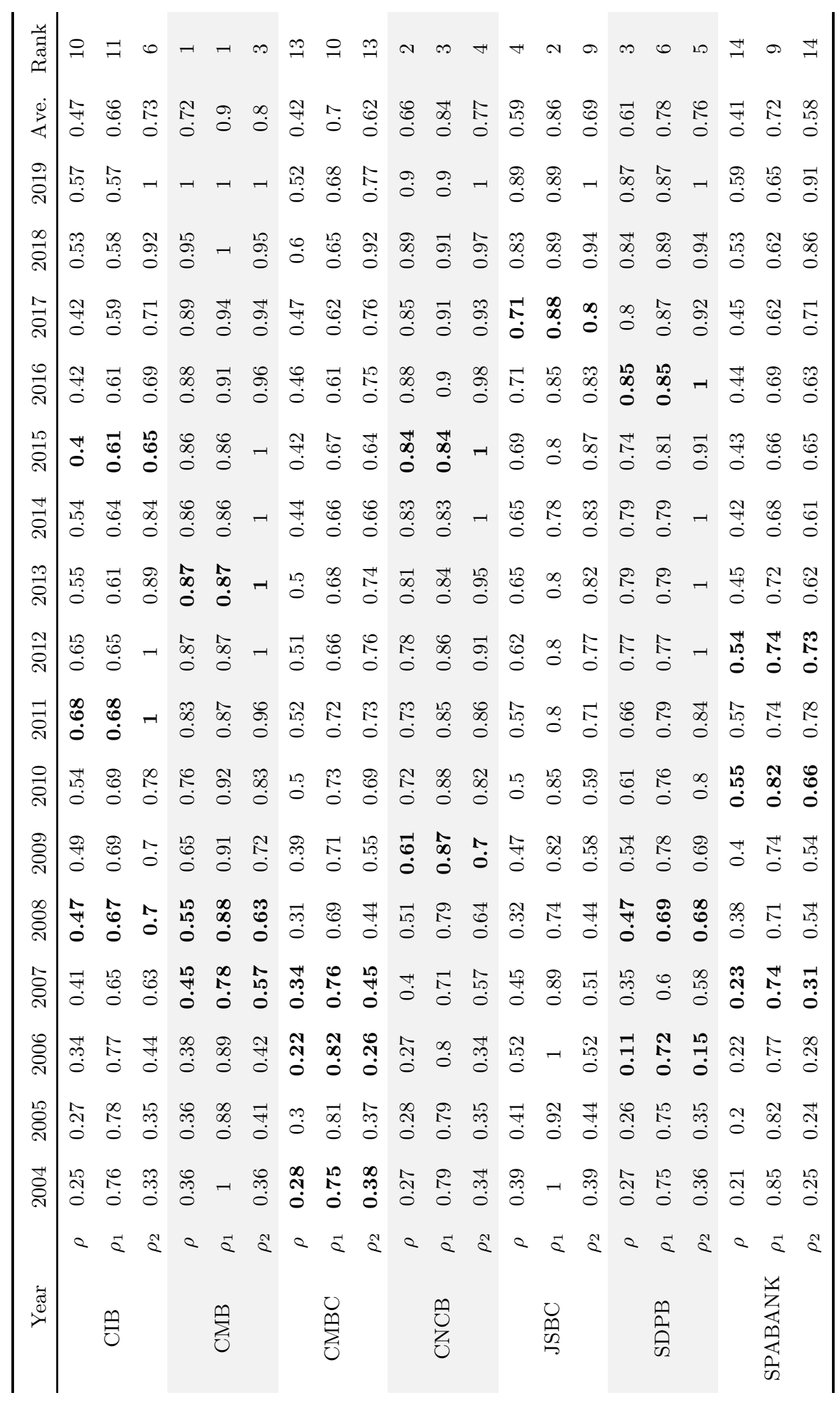




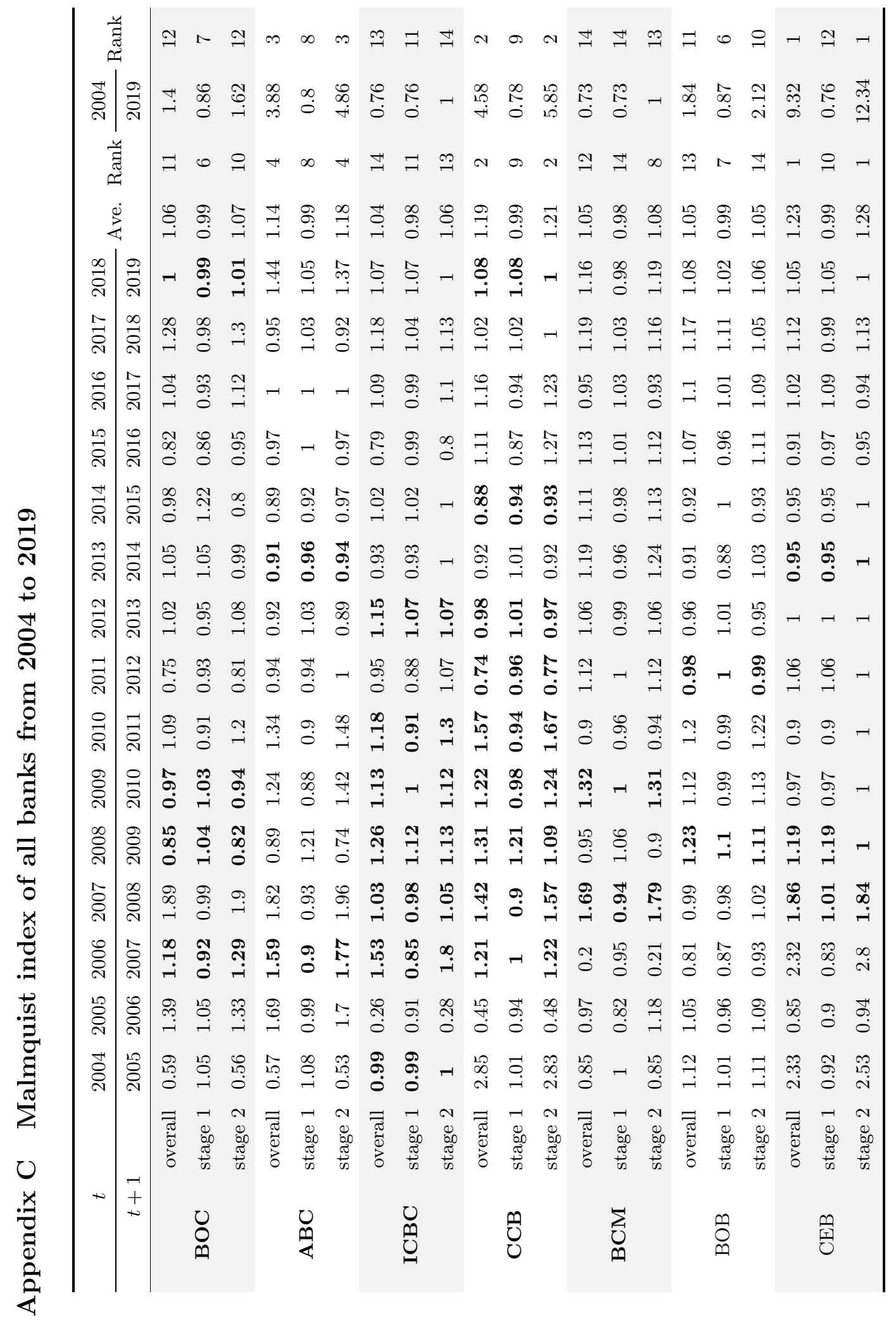




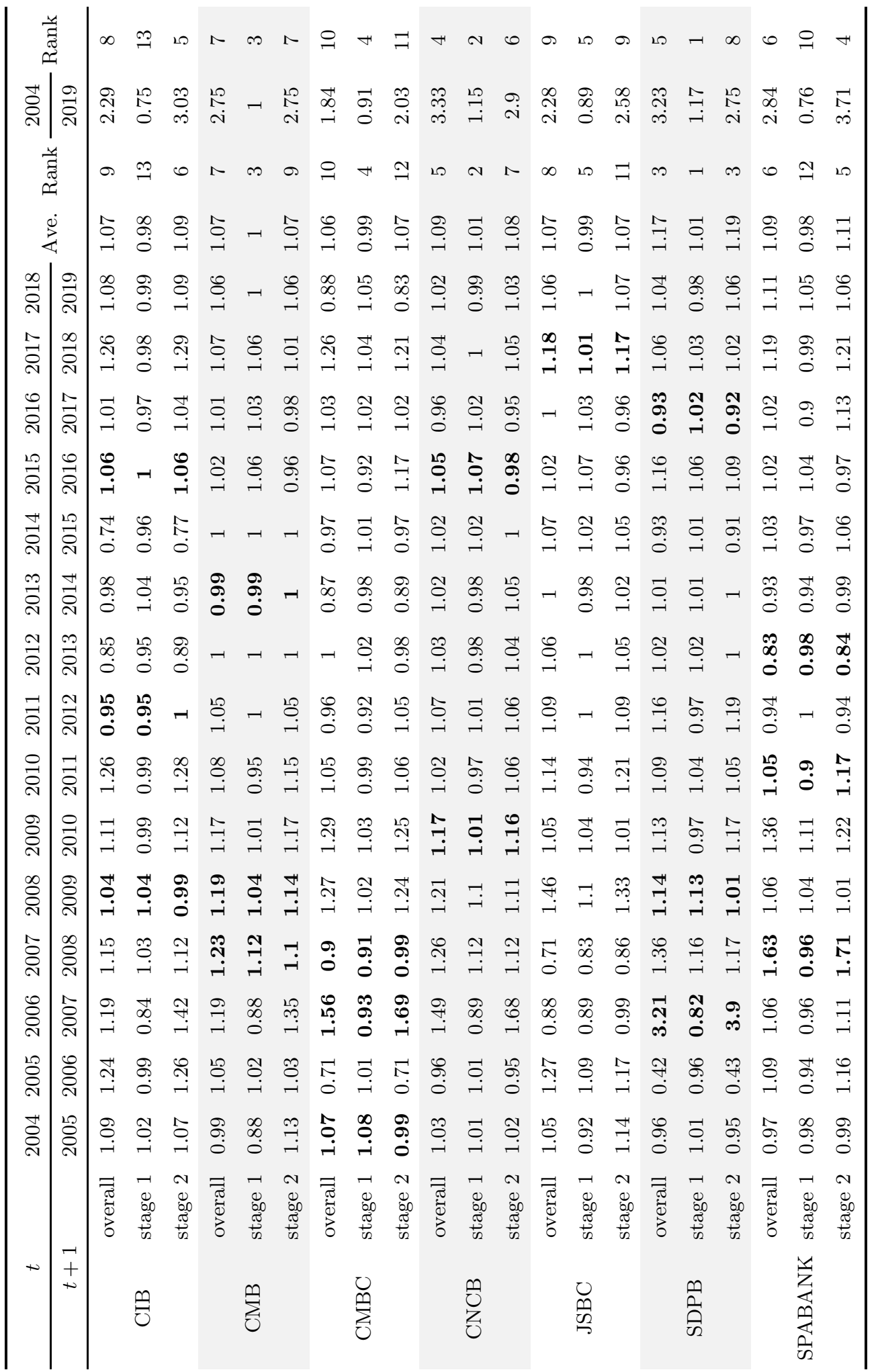




\section{Appendix D Decomposition of GMI into EC and TC}

\begin{tabular}{|c|c|c|c|c|c|c|c|c|c|}
\hline \multirow{2}{*}{ Banks } & \multirow{2}{*}{ Stages } & \multicolumn{4}{|c|}{$\mathrm{EC}$} & \multicolumn{4}{|c|}{$\mathrm{TC}$} \\
\hline & & 2004,2019 & Rank & Ave. & Rank & 2004,2019 & Rank & Ave. & Rank \\
\hline \multirow{3}{*}{ BOC } & overall & 0.99 & 6 & 1.01 & 4 & 1.41 & 12 & 1.06 & 11 \\
\hline & stage 1 & 0.99 & 6 & 1.08 & 5 & 0.87 & 8 & 0.99 & 7 \\
\hline & stage 2 & 1 & 5 & 0.96 & 11 & 1.62 & 12 & 1.08 & 8 \\
\hline \multirow{3}{*}{$\mathrm{ABC}$} & overall & 0.95 & 8 & 1 & 12 & 4.08 & 3 & 1.15 & 4 \\
\hline & stage 1 & 0.95 & 8 & 1.03 & 9 & 0.84 & 13 & 0.99 & 9 \\
\hline & stage 2 & 1 & 11 & 1 & 6 & 4.86 & 3 & 1.18 & 4 \\
\hline \multirow{3}{*}{ ICBC } & overall & 0.88 & 11 & 1 & 13 & 0.87 & 13 & 1.05 & 13 \\
\hline & stage 1 & 0.88 & 13 & 1.03 & 7 & 0.87 & 9 & 0.99 & 10 \\
\hline & stage 2 & 1 & 6 & 0.99 & 10 & 1 & 14 & 1.06 & 13 \\
\hline \multirow{3}{*}{$\mathrm{CCB}$} & overall & 0.89 & 10 & 1.01 & 5 & 5.15 & 2 & 1.22 & 2 \\
\hline & stage 1 & 0.89 & 11 & 1.17 & 1 & 0.88 & 7 & 0.99 & 6 \\
\hline & stage 2 & 1 & 9 & 0.83 & 14 & 5.85 & 2 & 1.23 & 2 \\
\hline \multirow{3}{*}{ BCM } & overall & 1 & 5 & 1 & 10 & 0.73 & 14 & 1.05 & 12 \\
\hline & stage 1 & 1 & 5 & 1 & 13 & 0.73 & 14 & 0.98 & 14 \\
\hline & stage 2 & 1 & 7 & 1 & 7 & 1 & 13 & 1.08 & 10 \\
\hline \multirow{3}{*}{$\mathrm{BOB}$} & overall & 0.97 & 7 & 1 & 8 & 1.9 & 11 & 1.05 & 14 \\
\hline & stage 1 & 0.97 & 7 & 1.06 & 6 & 0.9 & 5 & 0.99 & 5 \\
\hline & stage 2 & 1 & 12 & 1 & 2 & 2.12 & 11 & 1.05 & 14 \\
\hline \multirow{3}{*}{ CEB } & overall & 0.85 & 12 & 0.99 & 14 & 10.93 & 1 & 1.26 & 1 \\
\hline & stage 1 & 0.85 & 14 & 1.02 & 10 & 0.89 & 6 & 0.99 & 8 \\
\hline & stage 2 & 1 & 2 & 1 & 5 & 12.34 & 1 & 1.28 & 1 \\
\hline \multirow{3}{*}{ CIB } & overall & 1.05 & 3 & 1.01 & 6 & 2.18 & 10 & 1.07 & 10 \\
\hline & stage 1 & 0.9 & 10 & 1.13 & 2 & 0.84 & 12 & 0.99 & 13 \\
\hline & stage 2 & 1.17 & 1 & 0.99 & 9 & 2.6 & 9 & 1.08 & 9 \\
\hline \multirow{3}{*}{ CMB } & overall & 1 & 4 & 1 & 9 & 2.75 & 6 & 1.07 & 8 \\
\hline & stage 1 & 1 & 4 & 1 & 12 & 1 & 1 & 1 & 1 \\
\hline & stage 2 & 1 & 3 & 1 & 4 & 2.75 & 6 & 1.07 & 11 \\
\hline \multirow{3}{*}{ CMBC } & overall & 0.82 & 13 & 1 & 11 & 2.26 & 9 & 1.07 & 7 \\
\hline & stage 1 & 1.07 & 3 & 1.01 & 11 & 0.84 & 11 & 0.99 & 12 \\
\hline & stage 2 & 0.76 & 14 & 1.12 & 1 & 2.68 & 8 & 1.09 & 6 \\
\hline \multirow{3}{*}{ CNCB } & overall & 1.16 & 2 & 1.01 & 3 & 2.86 & 5 & 1.09 & 6 \\
\hline & stage 1 & 1.16 & 2 & 1.03 & 8 & 0.99 & 2 & 1 & 3 \\
\hline & stage 2 & 1 & 10 & 1 & 8 & 2.9 & 5 & 1.08 & 7 \\
\hline
\end{tabular}




\begin{tabular}{|c|c|c|c|c|c|c|c|c|c|}
\hline \multirow{2}{*}{ Banks } & \multirow{2}{*}{ Stages } & \multicolumn{4}{|c|}{$\mathrm{EC}$} & \multicolumn{4}{|c|}{$\mathrm{TC}$} \\
\hline & & 2004,2019 & Rank & Ave. & Rank & 2004,2019 & Rank & Ave. & Rank \\
\hline \multirow{3}{*}{ JSBC } & overall & 0.9 & 9 & 1 & 7 & 2.54 & 8 & 1.07 & 9 \\
\hline & stage 1 & 0.9 & 9 & 1.1 & 4 & 0.98 & 3 & 1 & 2 \\
\hline & stage 2 & 1 & 4 & 0.94 & 12 & 2.58 & 10 & 1.07 & 12 \\
\hline \multirow{3}{*}{ SDPB } & overall & 1.2 & 1 & 1.02 & 2 & 2.69 & 7 & 1.2 & 3 \\
\hline & stage 1 & 1.2 & 1 & 0.98 & 14 & 0.98 & 4 & 1 & 4 \\
\hline & stage 2 & 1 & 8 & 1 & 3 & 2.75 & 7 & 1.19 & 3 \\
\hline \multirow{3}{*}{ SPABANK } & overall & 0.78 & 14 & 1.03 & 1 & 3.65 & 4 & 1.14 & 5 \\
\hline & stage 1 & 0.88 & 12 & 1.13 & 3 & 0.86 & 10 & 0.99 & 11 \\
\hline & stage 2 & 0.88 & 13 & 0.92 & 13 & 4.22 & 4 & 1.16 & 5 \\
\hline \multirow{3}{*}{ Ave. } & overall & 0.96 & 3 & 1 & 2 & 3.14 & 2 & 1.11 & 2 \\
\hline & stage 1 & 0.98 & 2 & 1.06 & 1 & 0.89 & 3 & 0.99 & 3 \\
\hline & stage 2 & 0.99 & 1 & 0.98 & 3 & 3.52 & 1 & 1.12 & 1 \\
\hline
\end{tabular}

